\title{
UNDERSTANDING EARLY AULOI: INSTRUMENTS FROM PAESTUM, PYDNA AND ELSEWHERE
}

\author{
STEFAN HAGEL*
}

AвSTRACт: Starting from data on the 'Paestum' or 'Poseidonia' aulos established by Paul and Barbara Reichlin-Moser and Stelios Psaroudakēs, the 'Pydna' aulos, and comparable finds of early, mainly six-hole one-hole-shift, doublepipe fragments, possible musical interpretations of this important instrument type of the early Classical Period are considered. Probable pitches and intervals are assessed by means of well-tested software and confirmed experimentally; the required double reeds of a much longer type than known from later periods are shown to be substantiated by iconographic and literary testimony. The harmonic analysis of the instruments proposes the notion of a rudimentary tetrachordal structure, with equally divided tetrachords, which is both plausible in terms of music-ethnological parallels and the development of ancient musical theory. Some of the studied instruments appear to adhere to an early pitch standard, seemingly coinciding with the typical cithara octave. Critical evaluation of literary sources finally leads to a cautious interpretation as 'Lydian' instruments.

When I first set out to make sense of the archaeological remains of ancient double pipes, I started from the list provided by Martin L. West ${ }^{1}$. By then, no known pair of pipes had survived in a state that would have provided reliable data. The bone aulos kept in Copenhagen had obviously been restored in an entirely wrong way ${ }^{2}$, while the wooden Elgin pipes had been increasingly warping with time, causing measurements to diverge considerably between publications ${ }^{3}$. The well-preserved Louvre aulos, on the other hand ${ }^{4}$, is probably significantly younger, from the Ptolemaic or Roman period, and all the rest were single pipes and smaller fragments. West, while rightly criticising earlier attempts at establishing the missing lengths of tubing and reeds and in this way the instrument's musical scales ${ }^{5}$, offered only rough calculations, based merely on fingerhole distances. For most of the early examples, he set out from the assumption that they played a perfect fourth between thumb hole and small-finger hole, which seemed to bear out meaningful results. But would it be reasonable to attribute a simple single rule to such a variety of finds from different locations, periods, sizes, and contexts?

\footnotetext{
* Österreichische Akademie der Wissenschaften, Institut für Kulturgeschichte der Antike (Stefan. Hagel@oeaw.ac.at).

1 West 1992: 97-100.

2 Olsen 1968; Psaroudakes 2002: 364, pl. 24; cfr. 338, n. 23.

3 Curtis 1914: 100-102; Schlesinger 1939: 411-20; Letters 1969: 266-67; Psaroudakes 2002: 363, pl. 23.

4 Bélis 1984; Hagel 2004 and 2014.

5 Schlesinger 1939; Letters 1969.

6 For significant iconographic differences in the size of instruments played by adults in different contexts cfr. Hagel 2009: 328-332, 346, n. 45.
} 
Realising that a proper evaluation of potential aulos scales would require more precise calculations which account for the diameters of bores and fingerhole sizes no less than the hole positions, I went on to write the required software. With its help, I have since been able to expose the musical secrets of quite a few better-preserved auloi - but these were all from later periods ${ }^{7}$. As any newcomer to the field of ancient music, I had been more enthusiastic about reconstructing sounds from the Classical era; but the oldest auloi stubbornly refused to make much sense ${ }^{8}$. However, while I was busying myself with other aspects of ancient music history, two almost complete instruments were published, one from Paestum, dated to about $480 \mathrm{BC}$, the other from Pydna, about a century younger ${ }^{9}$. Although the two pairs of pipes are of slightly different size, their resemblance not only in general appearance, but also in terms of relative lengths and fingerhole placement is astounding, given their different age and provenance from quite different regions within the wider Greek world. On a cursory glance, they appear to represent a particular, well-defined instrument type. Naturally, their excellent preservation called for playable reconstructions by musicarchaeologically-minded colleagues. So the question of suitable reed lengths and accordingly a musical interpretation re-emerged with unprecedented urgency; at an aulos workshop in Tarquinia, centred on reed making, eminent music archaeologist Chrēstos Terzēs asked me about my opinions. By then I knew what my answer had to be in terms of instrument physics and my understanding of ancient music; but at the same time I was afraid that the figures I could provide would appear unlikely for another reason. My solution required reeds that were longer than any that I had predicted or built for other auloi. So much longer, actually, that I had refrained from publishing the results, in the hope to discern some error in my reasoning in the future. However, my mistake had been on the other side; too long had I viewed the iconographic evidence with the eyes of earlier scholars. As so often, my coming out resulted in a great relieve, and I was finally able to realise that the figures that my software predicted were in best congruence not only with the iconography but also with the relevant text.

On the very same day, Chrēstos went on to preparing reeds according to my specification for his replica. I did so later, when I had completed printable models of the instruments. Robin Howell, when building an instrument for Barnaby Brown, who had followed the conversation at Tarquinia, also asked for my measurements. As these did not immediately appeal to his instinct as an experienced maker of exquisite instruments, we discussed the matter in an extensive e-mail exchange. When having tested a few alternative ideas, however, Robin accepted the originally predicted values as the ones optimally suited for the instrument; in many months of exploring and performing on the instrument, Barnaby Brown has since validated

7 Hagel 2004, 2008, 2010, 2012a, 2013, 2014 and 2019a.

8 Cfr. Hagel 2004: 381.

9 Banou 1998; Psaroudakes 2008 and 2014; Reichlin, Reichlin-Moser 2015. 
their practicality ${ }^{10}$. In the course of all this, my results have been leaked to the internet public, against my scholarly cautioning. Fortunately, I can still stand by them, and this here is finally the respective publication.

\section{Interpreting the Paestum aulos}

Calculation would need to start from as precise measurements as possible. Obtaining these is not always a straightforward task when it comes to the remains of ancient pipes, where even bone parts may have suffered distortion, not to mention losses. Regarding the pair from Paestum - the Poseidonia aulos, as Stelios Psaroudakès would insist on calling it, giving precedence to the ancient cultural context rather than the later name of the find spot - it is therefore no wonder that the measurements published by Psaroudakēs on the one hand, and Reichlin, Reichlin-Moser on the other differ slightly. Most of the divergences, however, are in the range of a fraction of a millimetre, showing what excellent work both publications are based on. Only for a single hole, the lowest on the lower pipe, do the figures differ by as much as $1.5 \mathrm{~mm}$; that far down the pipe, even this will not affect our results in a significant way. A more noticeable discrepancy regards the length of the highest part of the higher pipe. While Psaroudakēs finds that the part containing neck and bulb originally went into the socket on the cylindrical main tube only about as far as its counterpart on the higher pipe, i.e. less than $6 \mathrm{~mm}$, Reichlin and Reichlin-Moser push it in no less than $9 \mathrm{~mm}$. As the length in question affects neither the span between fingerholes nor that between fingerholes and exit, however, this divergence has no bearing on the playable notes; the difference of about $3.5 \mathrm{~mm}$ will instead translate to a difference of assumed reed length. The reed lengths, in turn, cannot anyway be established with precision, because the upper rim of the fragile reed insert was irretrievably lost on both pipes. Since the overall shape of such parts is well known, though, the missing length can be established within a margin of a few millimetres.

Let us start from a calculation based on the measurements given in the very detailed drawing provided by Reichlin and Reichlin-Moser. As usual, we approach the question of an optimal reed configuration from a combination of two factors: (1) the pair of pipes ought to play a maximum of concords - defined, according to the ancients, as octaves, fifths, and fourths, in addition to unisons, and (2) the effective reed lengths should not differ too much between the two pipes of a pair. For assessing the second point, we need to keep in mind that the bulbs of both pairs are broken at different lengths. Fig. 1 provides a visualisation of the effect of all combinations of reed lengths from 0 to $200 \mathrm{~mm}$, with greater numbers of resulting concords expressed as darker shades of grey. Identical reed lengths on both pipes are found in the marked diagonal.

10 Brown 2018: 10. 


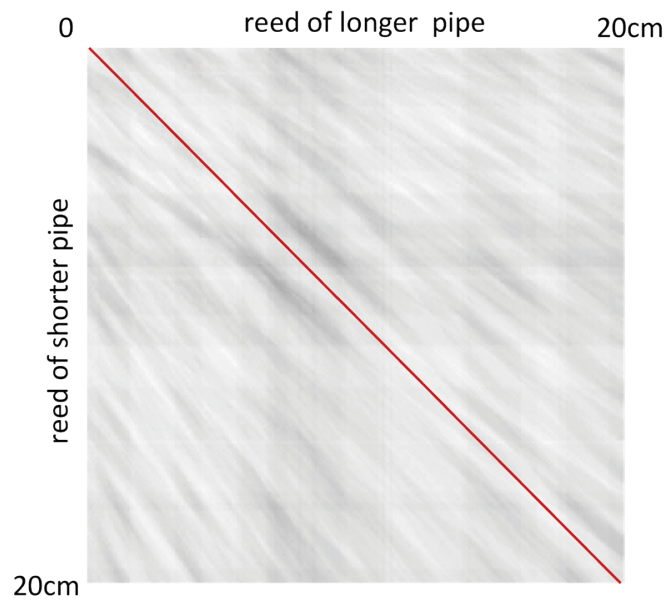

Fig. 1 - Predicted number of intervals deviating form pure unisons, octaves, fifths, and fourths by no more than 20 cents for different combinations of effective lengths of lost parts plus reeds on the Paestum aulos.
The strongest maximum occurs for an extension of $79.5 \mathrm{~mm}$ beyond the extant tubing on the longer pipe, and $68.5 \mathrm{~mm}$ on the shorter. Part of this difference is accounted for by the differently broken bulbs. That which Reichlin, Reichlin-Moser assign to the shorter pipe measures between $64.62 \mathrm{~mm}$ (Psaroudakēs) and $65.67 \mathrm{~mm}$ (Reichlin and Reichlin-Moser), the other one only $60 \mathrm{~mm}$. The attribution of the shorter bulb fragment to the longer pipe accords with our results, which require a longer extension on that pipe. On the assumption that both bulb-plus-neck parts had originally been of identical length, therefore, about $5 \mathrm{~mm}$ are subtracted from the $11 \mathrm{~mm}$ difference in reed length, leaving us with a variance of $6 \mathrm{~mm}$. On long reeds, a divergence of effective $6 \mathrm{~mm}$ is certainly within the range that may be caused by internal differences between the reeds. We will address this later; suffice it here to say that it is comforting to find the longer effective reed on the longer pipe. On the other hand, as we have said, Reichlin and Reichlin-Moser push the bulb belonging to the shorter pipe further in than does Psaroudakês; for the latter, the shorter pipe would therefore require a smaller extension. Psaroudakēs' data thus increase the divergence in required reed length to about $9.5 \mathrm{~mm}$. This is not decisive in any way; even such a difference might be attributed to the disparity of the reeds, and part of it may anyway have been absorbed by different original bulb lengths.

The pitches and intervals resulting from the optimal extensions are detailed in fig. 2. As expected, the rows of fingerholes on the two pipes are shifted against each other only by a single hole. From the figure it becomes clear that the pitches from corresponding holes are indeed in excellent agreement, so that five pitches can be played in unison from open holes ${ }^{11}$. When counting all consonances between the two pipes that do not diverge from perfection by more than 20 cents - the tenth part of a tone, less than a syntonic comma - we find no less than fifteen.

${ }^{11}$ Note that aulos fingerholes, especially of the early types with which this survey is solely concerned, are of such a large size and cross so thin a wall that their pitch is hardly affected by cross fingering, i.e. closing other fingerholes further down the instrument, in the way many modern wind instruments are played. 


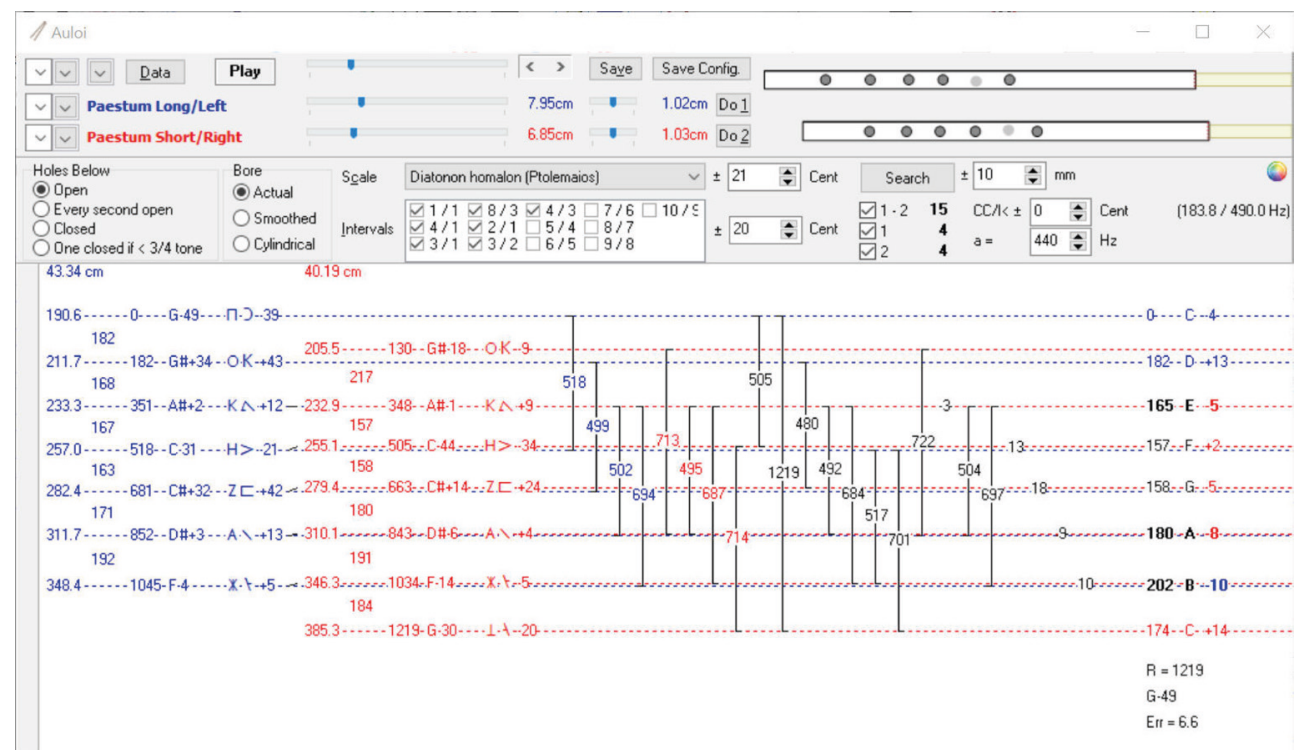

Fig. 2 - Predicted optimal configuration of effective reed lengths on the Paestum aulos. The coloured rows specify, for each pipe: frequencies in Hertz; steps in cents; distances from overall bass note in cents, modern note equivalences based on a concert pitch of $a^{\prime}=440 \mathrm{~Hz}$, with deviation in cents; approximate ancient note equivalences, based on a concert pitch of $\mathrm{K}<=245 \mathrm{~Hz}$, with deviation in cents.

Interestingly, three of these include a note played from the exit of a pipe, with all side holes closed: the longer pipe thus plays the octave of the highest note on the higher pipe as well as a fourth with the latter's second lowest fingerhole; the shorter pipe, a fifth with the second highest of the longer. This is of the greatest consequence, because it strongly suggests that these notes were intentionally tuned by the makers, even though they are not normally available: with all five fingers closing their respective holes, the resulting note would not be emitted by the full pipe, but by the lowest side hole, which cannot be reached by any finger. If the pipe exit was nevertheless tuned to harmonic intervals, the assumption appears almost inevitable that the performers would sometimes have stopped the lowest side holes with some kind of plugs, in order to avail themselves of alternative bass notes.

The central steps emerge as being of almost identical sizes, dividing perfect fourths into almost equal parts ( 498 cents : $3=166$ cents). At the fringes, however, we find distinctly larger intervals, close to whole tones. The typical 'tone' of Greek theory is defined as the difference between a fifth and a fourth, corresponding to a ratio of $9: 8$ or 204 cents; compare the step of 217 cent at the bottom of the short pipe. Ancient theorists also reckoned with larger and smaller 'tones' within various tetrachord divisions; the 'small' tone of 10:9, for instance, amounts to 182 cents; compare the lowest interval of the long pipe as well as the highest of the shorter. 
Before we delve further into the harmonic implication of such a pipe, we need to address the question that had irritated me for quite a while: are we justified in postulating reeds of such length, and if so, what would be their purpose? After all, later ancient auloi were evidently equipped with much shorter reeds, much like those on modern reed instruments (albeit of very different make). The Louvre aulos as well as the Pompeii auloi call for reeds of about $40 \mathrm{~mm}$ effective length, the small Berlin aulos for $25-35 \mathrm{~mm}$; one of the latter's reeds had even been preserved. In contrast, the proposed interpretation of the Paestum aulos incorporates extensions of 68 to $80 \mathrm{~mm}$, divided between the actual reed protruding from its insert and the insert itself into which it went. Judging from better preserved similar items, Psaroudakēs estimates the original length of the bulb + neck parts as about $72.6 \mathrm{~mm}$. If we accept this value, we end up with an effective reed length of about $67 \mathrm{~mm}$ for the longer, and $62 \mathrm{~mm}$ for the shorter pipe.

\section{Interpreting the Pydna aulos}

What about the similar pair of pipes unearthed at Pydna? Here we need to rely on Psaroudakēs' measurements, following his astute arguments concerning the restoration of the parts. The upper end of one pipe survives, so that the corresponding end of the other one could be extrapolated with sufficient precision. Accordingly, calculated extensions are here immediately understood as effective reed lengths. In fact, the optimal lengths are almost equal, as can be gleaned from fig. 3, where the darkest spot falls almost exactly on the diagonal.

The resulting configuration of intervals

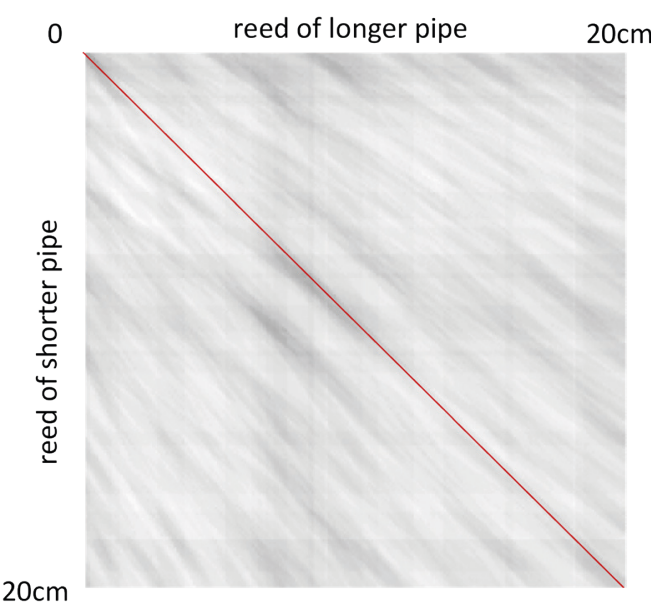

Fig. 3 - Predicted number of intervals deviating form pure unisons, octaves, fifths and fourths by no more than 20 cents for different combinations of effective lengths of reeds on the Pydna aulos. is quite similar to that on the Paestum instrument, as emerges from a comparison of fig. 4 with fig. 2 above. Once more we find a tripartite fourth between larger intervals that broadly fall into the category of 'tones'. Most importantly, the Pydna aulos also incorporates an octave between its lowest and highest notes, a fourth - but not a fifth! - above the bass note of the longer, and a fifth - but not a fourth! above that of the higher pipe. Some of the precise interval sizes show an uncanny coincidence, being identical to the hundredth part of a tone: between corresponding notes on both instruments we find pairs such as 505/504, 684/684, 517/517, 701/701, 
$722 / 721$. Here it may be necessary to emphasise once more that the respective reed configurations have been worked out independently by a computer algorithm, without any manual interference.

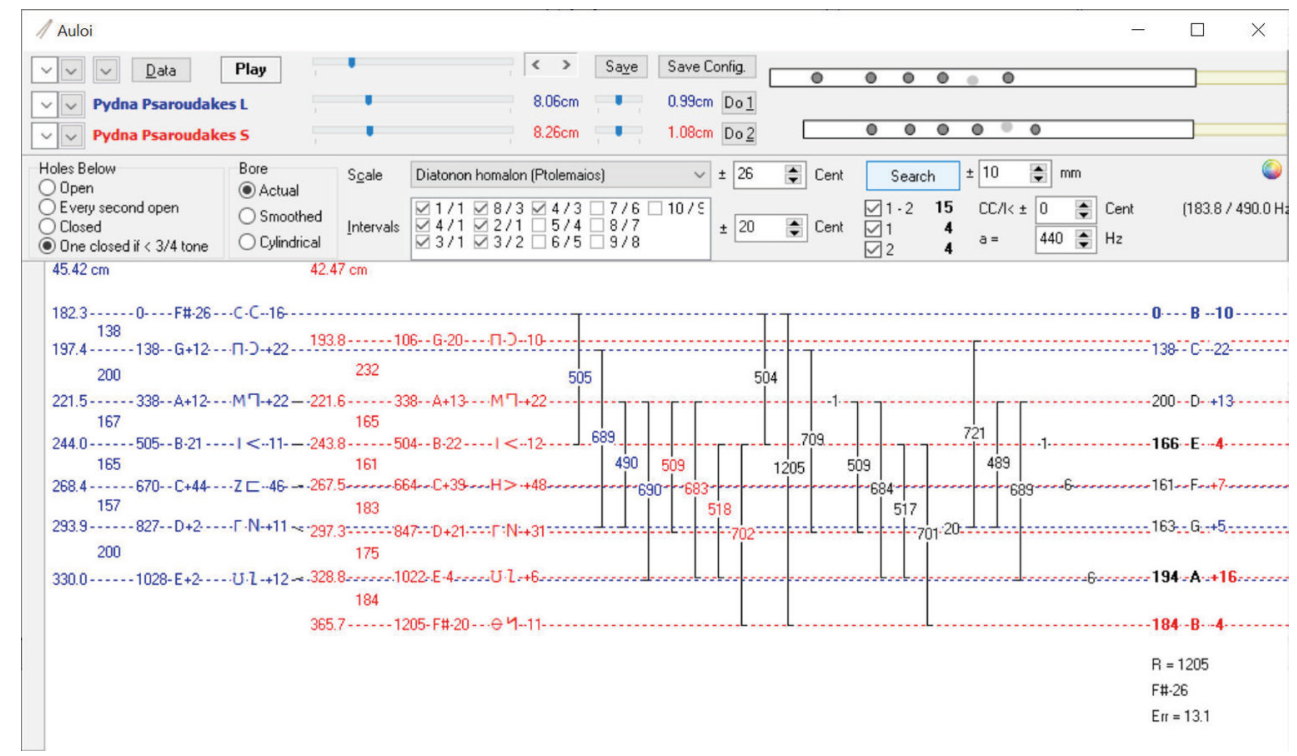

Fig. 4 - Predicted optimal configuration of effective reed lengths on the Pydna aulos. The coloured rows specify, for each pipe: frequencies in Hertz; steps in cents; distances from common bass note in cents, modern note equivalences based on a concert pitch of $a^{\prime}=440 \mathrm{~Hz}$, with deviation in cents; approximate ancient note equivalences, based on a concert pitch of $\mathrm{K}<=245 \mathrm{~Hz}$, with deviation in cents.

But there are also differences. Firstly, the pairs are of different size and therefore play at different pitches, almost a semitone apart. That may of course not mean much; in modern times, concert pitch has varied more within smaller geographic distances. More importantly, the note from the lowest side hole on the longer pipe is drilled a whole tone below its upper neighbour on the Pydna instrument, while the maker of the Paestum aulos put it further up. As a result, the steps on both sides of that hole appear inverted on the two instruments. As such a big discrepancy, easily visible to the eye, can hardly result from carelessness on the part of the artisans, on instruments that appear to be so skilfully tuned in other respects, it seems that the two instruments are not meant to be entirely identical, after all.

This single major divergence set apart, the results for the two pairs appear to corroborate each other, in this way adding confidence in the idea of specifically long reeds. Actually, the larger instrument requires even larger reeds, extending more than $80 \mathrm{~mm}$ from the insert. 


\section{Evidence for long reeds}

But we need not rely on organological inferences alone. Further confirmation can be found in Theophrastus' well-known chapter on cane suitable for pipe and reed making, which includes some detail on how the plant stem is prepared for the actual manufacturing. The passage that concerns us here deals with cutting the dried reeds:

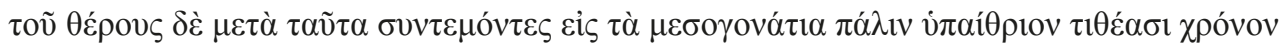

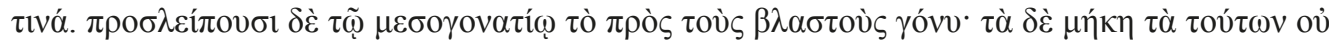

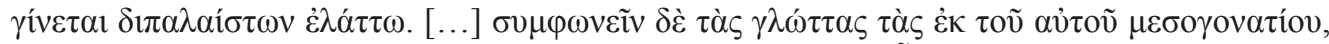

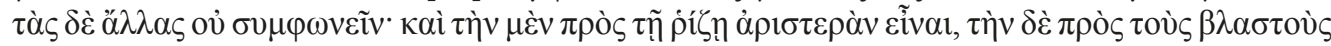

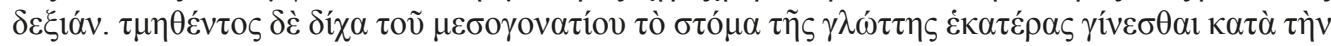

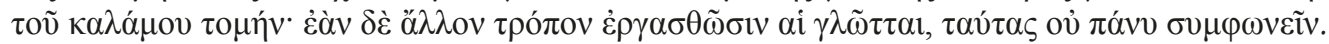

In the following summer they cut it in internodia and put it once more in the open for some time. Each internodium retains the node towards the blossom, their length being no less than two palms' breadth. [...] The tongues from one and the same internodium, they say, are in concord, but not the others; and the one closer to the root is the left-hand, the one closer to the blossom the right-hand [tongue]. When the internodium is cut in two, the opening of each tongue is fabricated at the cut of the cane. If the tongues are manufactured in another way, they are not in good concord, it is said.

(Theophrastus, Hist. plant. 4.11.6-7)

From Theophrastus' words it becomes clear that a suitable length of cane between two nodes yields no more nor less than two reeds, which optimally form a pair. If the author - or his source, which may have been local reed-makers - insists on a minimal dimension, this can hardly mean anything else than that a shorter internodium would not accommodate the required lengths. Two palms being the minimum for a pair plus the length of the node which is still attached to the piece at that stage, we must conclude that in Theophrastus' time no (professional?) aulos reed measured less than one palm minus half a node width. For a stem of suitable thickness for being inserted into one of our instruments, a node would typically have occupied hardly more than $10 \mathrm{~mm}$. Ancient measurements varied through cities and periods; so a palaistế might span between $75 \mathrm{~mm}$ and $83 \mathrm{~mm}$. Consequently, Theophrastus reckons that one reed ought be manufactured from a length of cane no shorter than $70 \mathrm{~mm}$.

To be sure, ancient reeds were not fabricated like modern bassoon or oboe reeds, by folding a strip of cane - in a way that might yield two reeds from different sides of the same piece. So much is clear from the expression "the mouth of each tongue", which must refer to the ends with the vibrating blades that produce the sound. Consequently there is no reason why the finished reeds should have been any shorter than the lengths of cane from which they were created. Within the organological horizon of Theophrastus' report, therefore, no aulos reed would have been shorter than about $70 \mathrm{~mm}$. Part of that length would have gone into the conical or flaring insert above the typical bulb. The depth of this insert is often marked by a clear step, which ensured that the cavity of the lower cylindrical part of the reed extended the 
bore of the instrument as smoothly as possible. Typical insert depths range between $14 \mathrm{~mm}$ and $17 \mathrm{~mm}$. By subtracting this length from the overall length of the reed we obtain a minimal physical reed extension of about $55 \mathrm{~mm}$. Effective reed lengths may somewhat differ from the physical lengths, but in practice I have normally found that the former are an excellent guide when preparing a reed for a reconstructed aulos. Bearing in mind that, if we take Theophrastus' words literally, these $55 \mathrm{~mm}$ are indeed the minimum, the required effective extensions of $62-67 \mathrm{~mm}$ on the Paestum aulos, an instrument for adult male hand and therefore one of the larger types ${ }^{12}$, seem very reasonable, and the $80 \mathrm{~mm}$ for the instrument from Pydna are hardly excessive either.

The apparent divergence between the two Paestum reeds is also in accord with the conventions described by Theophrastus, who assigns the lower part of the internodium to the left pipe. In the case of the Paestum pipes this was almost certainly the longer: thanks to the transversal displacement of the thumbholes to opposite sides, playing it with the left hand is significantly more convenient. Psaroudakēs has presented convincing arguments for taking the association between left and long (and therefore low in pitch) as the general rule in early auloi ${ }^{13}$. If both reeds were of almost identical physical length, as may be commended by aesthetic considerations, and of comparable wall thickness, the part that is taken from the lower part of the plant has a somewhat greater cavity, since the stem becomes narrower toward the top. Now an increase in the internal volume of the reed, when attached to a main bore of fixed diameter, increases the effective length of this reed, i.e. it behaves similar to a longer reed of smaller diameter. This effect would absorb a part of the greater length that our calculations have indeed predicted for the left, long Paestum pipe. It should however not be overestimated; even when the right-hand reed's internal diameter is assumed to be as much as $10 \%$ smaller, the divergence in required reed length is decreased only by one millimetre, from $5 \mathrm{~mm}$ to $4 \mathrm{~mm}$. On balance, the results from the Pydna pipe, where conversely, and unexpectedly, the short pipe would need a slightly longer reed, is closer to physical balance than are the Paestum results, even when corrected for potential internal reed diameter differences. And finally all the contemplated differences, which have boiled down to something around 3-4 mm, are overshadowed by the effects of the vibrating reed blades and how these are manipulated by the performers when tuning their instruments by adjusting the position of the reeds relatively to the lips. It is the shape of the blades that has the greatest effect on the sound and stability of pitch. Indeed the fact that both reed ends were manufactured from the two ends resulting from the central cut and therefore from identical diameters at the tip shows that ancient makers regarded it as paramount that the blades were as similar as possible.

12 Aristoxenus classifies auloi by size, not tonality, ranging from 'girls' to 'grown-up' and 'super-grownup' instruments: Harm. 1.20, p. 26.2-7 Da Rios; Ath. 634ef.

13 Psaroudakes 2008: 201-202; Psaroudakes 2014: 120. 


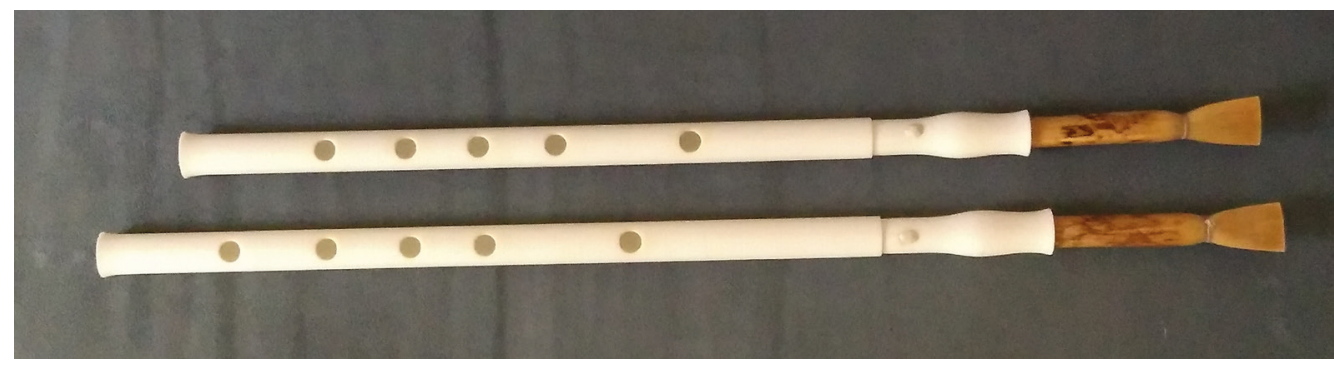

Fig. 5 - 3D-printed reconstruction (PA12 laser sintering) of the Paestum aulos, furnished with reeds constructed by the author.

\section{The nature of the reeds}

Fig. 5 gives an impression of the proportions of bone instrument and required reeds on the Paestum aulos. The initiated reader recognises the double reeds, as opposed to simple 'beating' single reeds as are used on all recent doublepipe instruments such as the argīul or the zummāralmiğwiz. Regarding the question which kind of reed the ancient Greek aulos (and the corresponding instruments in other cultures, especially those of the Italic peninsula) used, there has been considerable confusion in modern times. For the Roman-Imperial period, double reeds are well established by the iconographical sources ${ }^{14}$, and the reed preserved with the Berlin aulos, a Greco-Egyptian instrument, was of this kind, too. These reeds consisted of a lower cylindrical part that went into the insert, and an upper part, where the cylinder of the reed was flattened so as to produce a couple of blades, which were then scraped down according to the demands of the players. Similar reeds are still used on traditional instruments throughout Asia, such as the duduk, the guan or the bichiriki. Cylinder and blades were set apart by a constriction, which ensured the stability of the reed: without it, the distorted geometry of the blades would inevitably spread downwards over time.

The reed in fig. 5 is basically of the same type, distinguished from the reeds of later Antiquity only by the greater length of the cylindrical part, and it plays excellently. Nevertheless, in modern times some scholars and performers have argued for beating reeds. When preparing his seminal paper on the aulos in the late 19th century, Albert Howard had equipped his working models with single reeds, even those of auloi from Pompeii ${ }^{15}$, even though an experienced organologist such as Victor-Charles Mahillon would easily establish that a double reed fitted the instrument much better ${ }^{16}$. The idea of single reeds also featured among Kathleen Schlesinger's misapprehensions of ancient sources, though she actually believed that early auloi had been equipped with double reeds, and that the change to single

14 E.g. Byrne 2000; cfr. also Loret 1893; Closson 1930.

15 Howard 1893: 52-60.

16 Southgate 1915: 18. 
reeds was owed to musical refinement - a stance I find hard to follow, since unlike the modern clarinet-type reed, the type of single reed she has in mind would not normally permit controlling the intonation with the lip, as is so widespread with double reeds. In a tell-tale example of flawed reasoning, Schlesinger concludes from a passage in Ptolemy ${ }^{17}$ that the ancient author must have had the single 'beating' reed in mind ${ }^{18}$, obviously relying solely on the fact that Ptolemy talks about "the beating [agent]" ( $\tau$ ò $\pi \lambda \tilde{\eta} \tau \tau$ ov), which she naively equates with the organological usage of 'beating' in her native English, overlooking the fact that Ptolemy here compares the aulos to the windpipe and the reed to the glottis, which works like a double reed, and to which the term 'the beating [agent]' is also applied. In fact, the idea of 'beating' is here merely introduced as the commonplace term for any kind of sound-producing agent, going back to the beginnings of acoustics ${ }^{19}$. The similarity of glottis and aulos reed is also exploited by Galenus - after all, the glottis doubtless inherited its name from the reed mouthpiece ${ }^{20}$ :

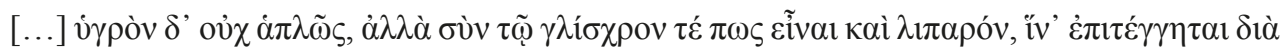

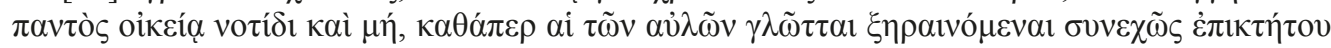

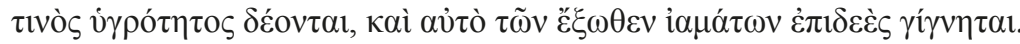

[...] but not simply moist, but with a greasy and oily quality, so that [the glottis] is wholly humidified by a moisture of its own and does not (such as aulos tongues, which always dry out and need some additional supply of humidity), come to require external remedy.

(Gal., De usu partium, 3.566.8-12)

In the German-speaking world and beyond, the book of Heinz Becker has been influential ${ }^{21}$. His arguments are partially confused, for instance when he first postulates modern-style folded reeds when criticising Howard, while referring to ancient flattened reeds immediately afterwards. More importantly, Becker could not yet know how much longer early auloi reeds had been and thus wrongly extrapolated from modern and Roman-period evidence. Of his two iconographical main witnesses for single reeds, none withstands closer scrutiny. The first is a vase painting showing a female who apparently pushes a reed into a pipe by with her index finger on the former's top ${ }^{22}$. Such an action would indeed seem preposterous, since it would almost inevitably damage the delicate blades. However, the act that is actually depicted was probably of a very different sort, one that is entirely familiar

17 Ptol., Harm. 1.3, p. 9.6-15 Düring.

18 Schlesinger 1939: 71.

19 Cfr. Archytas fr. $1 \pi \lambda \alpha \gamma \alpha$; ps.-Eucl. Sect. can. $1 \pi \lambda \eta \gamma \eta \dot{~ e t c . ~}$

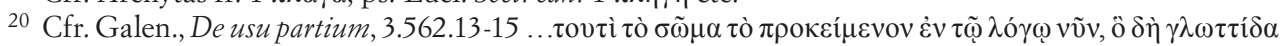

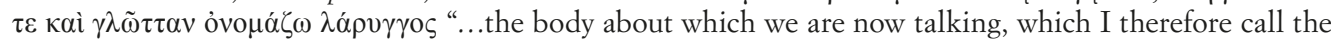
reed blade [glöttís] and tongue [glôtta, a term also used for the aulos reed] of the larynx"; for the necessity to moisten aulos reeds before playing, cfr. also ps.-Aristot., De audib. 802b.

${ }^{21}$ Becker 1966: 51-80; but cfr. Wegner 1949: 54. Single reeds are still assumed, without clear argument, in Steinmann, Reichlin 2006: 239-240.

22 London BM E 271, depicted also in West 1992: pl. 21. 
to all of us who have taken part in the resurrection of the auletic art: after finishing playing, the performer puts the protective reed cap back on, which also keeps the reed in the right shape and prevents it from opening up too much. Such reed caps are known from ancient depictions otherwise ${ }^{23}$; similar devices are described in the Persian treatise Kanz al-tubaf ${ }^{24}$ from the 14th century and still used for instance on the duduk.

Becker's second witness is a wall painting from an Etruscan Tomb, which he claims shows an actual depiction of a beating reed cut into a piece of cane; the painter would however have failed to show the mouthpiece inserted into the player's mouth, even though the latter is clearly shown during performance, with strongly inflated cheeks. That an artists chose to show a feature perceived as important even though it would actually be hidden from sight is not unparalleled; but in the context of Etruscan wall paintings and tiny slits in a piece of reed such an assumption amounts to special pleading. Moreover, that a painter would place such emphasis on such a small detail and still portray one of the tongues on the upside and the other on the downside, as would follow from Becker's interpretation, is even less likely. Moreover, the proportions in the painting would indicate that at least $8 \mathrm{~cm}$ of the reed would need to be taken into the mouth, which appears hardly possible with a single pipe and perfectly impracticable with two. If the lines that Becker sees are actually there, they may rather represent the ends of the thread that was used to constrict the reed below its blades ${ }^{25}$.

Similarly, Becker's claim that Theophrastus' ascription of a single glôtta to each pipe precludes a double reed appears to be inferred from his German understanding of what a Zunge ought to be, which he evidently understands to represent some flat flexible object. The Greek idea of an aulos glôtta, however, is based on the more general conception of a part that allows something to speak. At least, this must have been the conception of those who transferred the term to the glottis, as discussed above; thus I cannot see why we should need to ascribe a different view to Theophrastus.

23 E.g. Paquette 1984: A19 (London BM E 53), A (p. 129, Würzburg inv. 521) and most prominently the pipes behind the theatrical masks on a mosaic, where the artist took pains to represent the split in the piece as well as the loops of thread holding it together: Rome, MC 0392 (https://upload.wikimedia.org/wikipedia/ commons/2/28/Mosaic_of_the_theatrical_masks_-_Google_Art_Project_\%28crop_without_borders\%29. jpg). The caps could be connected by a thread, which would have helped keeping matching reeds together in the reed-box ( $\gamma \lambda \omega \tau \tau$ боко $\mu \tilde{i}$ ov); cfr. e.g. Naples National Museum inv. 80084, West 1992: pl. 17.

24 Tsuge 2013: 171.

25 For an aulos with threads pending from a region close to the player's mouth cfr. already the Hagia Triada sarcophagus from c. 1400 BC, https://upload.wikimedia.org/wikipedia/commons/7/75/Agia_ Triada\%2C_sarcophagus\%2C_long_side_1\%2C_limestone\%2C_fresco\%2C_1370-1320_ BC\%2C_AMH\%2C_145305.jpg. Note that a musical connection between that sarcophagus from Crete at the verge between Minoan and Mycenean culture on the one hand and Etruscan culture many centuries later on the other is less far-fetched than one might think: the shape of the lyre on the other side of the sarcophagus is never seen again in the Greek world, but resurfaces in Italy in the Classical Period; cfr. Lawergren 1993: 65-66. 


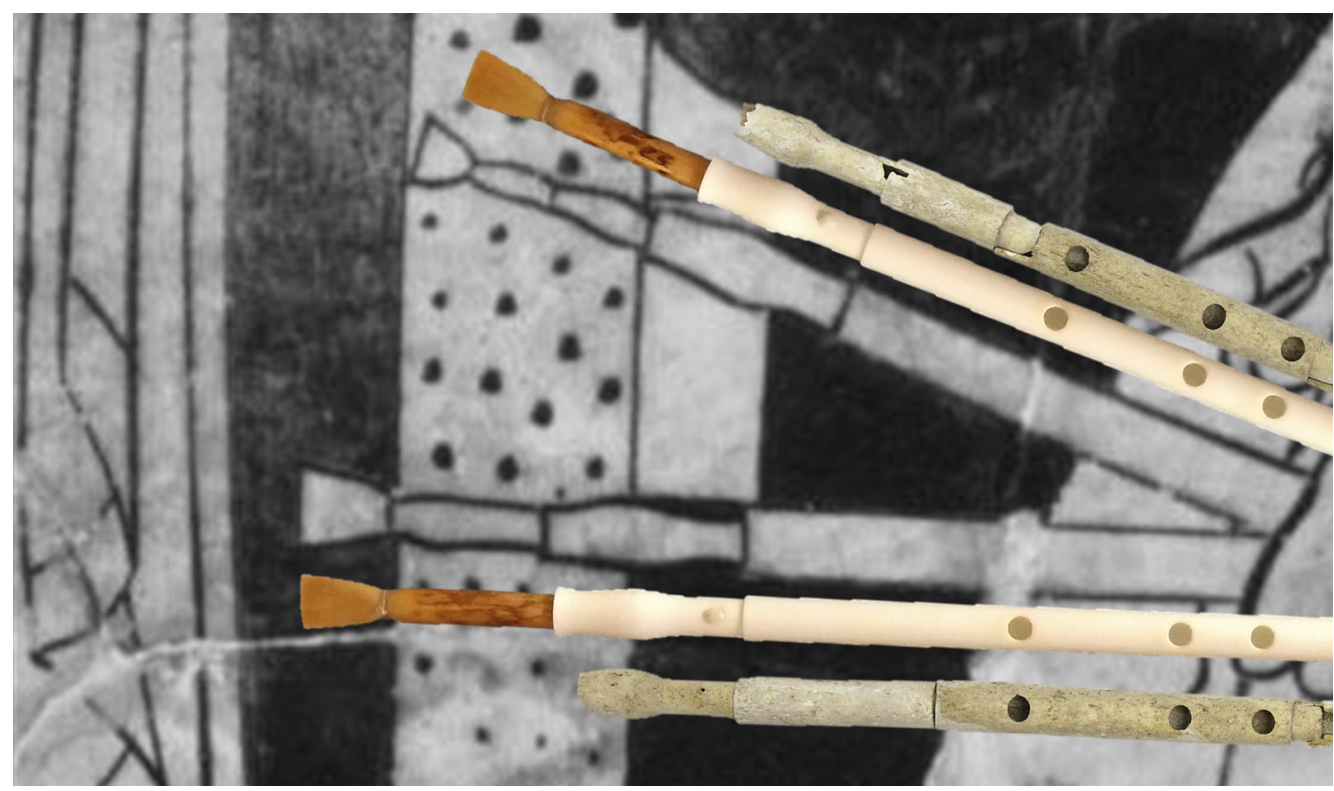

Fig. 6 - Proportion of bulb and reed on Tarquinia RC6843 and the Paestum aulos.

\section{Reed iconography}

Becker is certainly to be commended for printing and discussing evidence that runs contrary to his own claims. So his book includes a vase painting on which one of the pipes appears to be visually divided into the four sections he would have expected for double reeds but could not find anywhere else. At the same time, it is one of the few examples where the trapezoid form of the blades is clearly shown ${ }^{26}$. Becker's expectation was informed by the instruments from Pompeii and wooden pipes from the later period, which feature a clear demarcation between bulbs and reed inserts. On the early type, in contrast, the insert connects to the bulb in a smooth curve. Consequently there are only three marked boundaries which an artist might find worth depicting: the step between the main tube and the narrower neck below the bulb, the upper end of the pipe where the reed sticks out, once more in a step, and finally the constriction on the reed.

In fig. 6, the upper parts of the pipes from the painting are juxtaposed with the Paestum find and my printed model with suitable reeds. It emerges that our predictions are in excellent agreement with the representation as regards the proportions between bulb and reed. The pipe that is held horizontal provides the best match, including the size and shape of the blades of the reed. On the tilted pipe, on the other hand, something seems to have gone slightly wrong, and the cylindrical part of the reed is curiously wobbly as well as divided in the middle by an unexpected

26 Tarquinia RC6843; cfr. Paquette 1984: A30; Others include Paquette A13, A48, A55. 
line. Probably that line had originally been intended to represent the constriction; on second thought, the painter seems to have decided that this would make too short a reed and added some millimeters. This also explains the double bulging: on the other pipe we observe that the artist preferred representing the cylindrical part not by parallel lines, but widening towards the top, so that the constriction would stand out more clearly, and the entire structure appears more balanced. On the upper pipe, the originally shorter part shows a similar bulging, and when adding the extra length there was no better option than to draw this with another bulging.

This singularly meticulous representation helps us understand myriads of others with greatly varying attention to fine detail, which have given rise to various organological speculations that are not borne out by the archaeology. One is the idea that some auloi had been equipped with more than one bulb ${ }^{27}$. I have little doubt that the respective images merely exaggerate the artificial 'bulbing' of the lower part of the reed. The desire to display both the narrowing between bulb and insert part and the constriction of the reed in minute space and a given brush width would almost automatically lead to this effect. Quite contrarily, it has also been argued that the bore of the aulos would have narrowed down stepwise towards its blowing end ${ }^{28}$. This misconception was evidently prompted by painters who focused more on the fact that the cylinder of the reed is actually narrower than the main tube, let alone the bulb, and perhaps also, that the end of the reed, finally, is flattened ${ }^{29}$. Others again were satisfied with drawing a couple of straight lines, slightly converging towards the mouth of the player - compare the aulos player in the Tomb of the Diver - and perhaps indicating a few visible boundaries by simple strokes ${ }^{30}$.

I will finish the iconographical examples with another famous image, from the Etruscan variety of an apparently international aulos culture: the aulete in the Tomba dei Leopardi at Tarquinia. In fig. 7, the model of the Paestum aulos is scaled so as to match the size of his instrument. The correspondence is once more stupendous, starting from the relation between short and long pipe in the player's right and left hand, respectively, to the proportions of tube, bulb plus insert and reed, including its constriction, and up to the ranges of the fingerholes: the index fingers of both hands of the depicted performer are placed almost exactly where the corresponding holes on the Paestum instruments are located, and the same holds true for the left small finger, even though it is represented as (temporarily) placed under the instrument, presumably in order to facilitate the operation of the thumb on its hole. Only the span of the right hand appears exaggerated, whose small finger extends down to the region of the lowest side hole, which would not normally be fingered ${ }^{31}$.

27 E.g. Wegner 1949: 52-53; West 1992: 85. A beautiful example is found on the pyxis Boston MFA 98.887; cfr. http://mfas3.s3.amazonaws.com/objects/SL36557.jpg

${ }^{28}$ Najock 1996.

29 E.g. Paquette 1984: A8, A11, A21, A23, A35, A37, A49.

30 E.g. Paquette 1984: A12, A15, A21, A36, A38, A54.

31 Actually, I find it just manageable to cover that hole with my small finger, so the possibility cannot be ruled out that this hole might have been fingered while plugging its higher neighbour. 


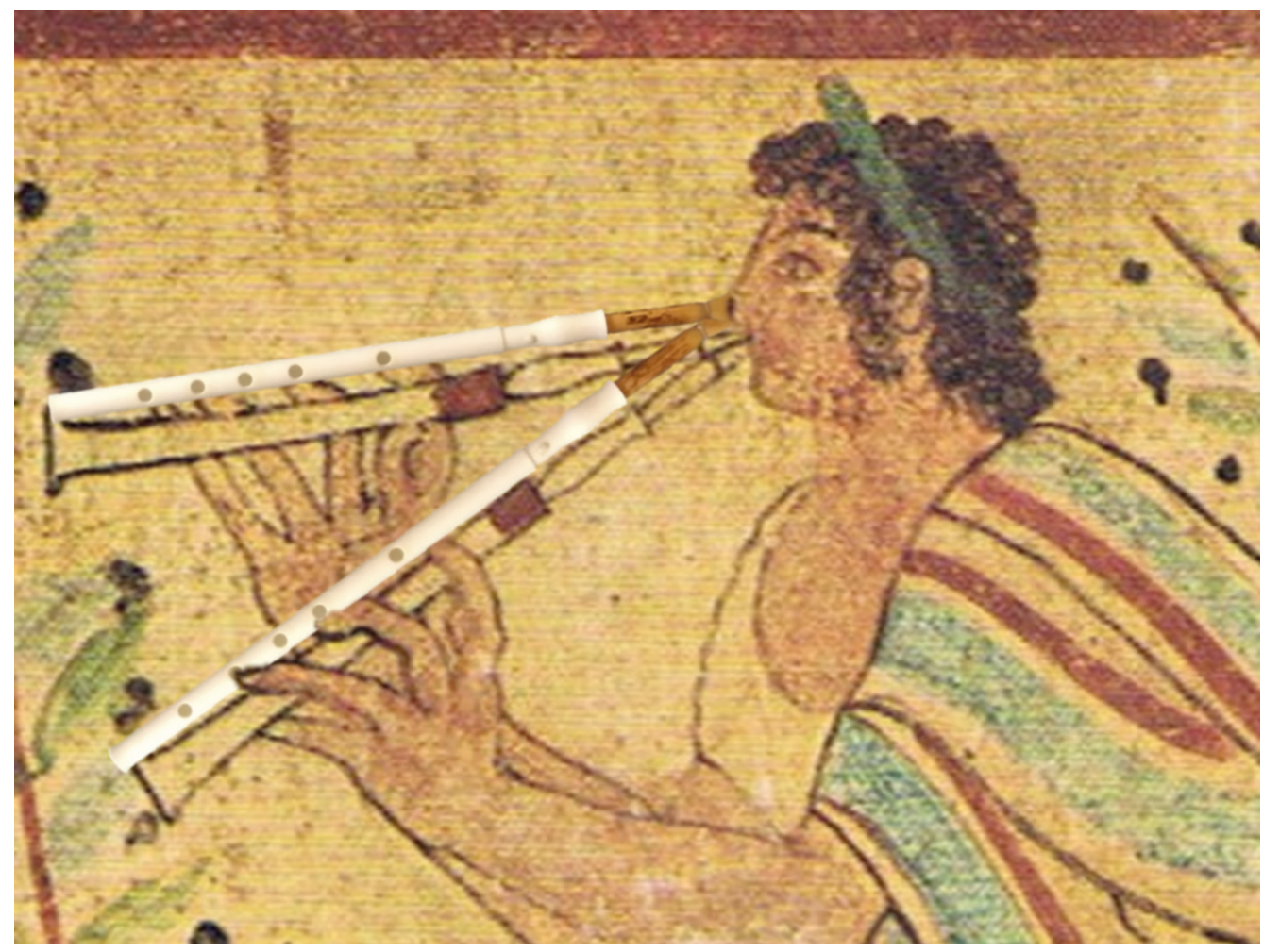

Fig. 7 - Proportion of tube length, bulb, reed and fingerhole/finger positions on the aulete from the Tomba dei Leopardi and the Paestum aulos.

Why, finally, would early aulos makers adopt such a different approach to reed length than we find it later in the Roman world? The answer may be very practical: whatever the reed is longer, the tube can be shorter. For bone tubes, this means an enormous advantage - even without the additional lengths, each instrument needed to be made from at least four sections, each consuming the usable part of one leg of an animal of the right age. Available material was less critical for wooden instruments; while drilling a perfectly straight bore was still easier in a shorter piece (the main tubes of the Elgin pipes are made in one piece), technical considerations may here have been of smaller importance than the intention of reproducing the shape of the more valuable bone instruments. The change to short reeds may have gone hand in hand with the development of metal-clad pipes, which were anyway much costlier, and which featured a reed insert that served as a tuning device ${ }^{32}$. At that period, then, wooden auloi like those in the Louvre and the Berlin Egyptian Museum would naturally imitate contemporary professional instruments. 


\section{Modern bypotheses about early pipe scales}

After we have established the length of the missing reeds with reasonable certainty, we can once more return to the harmonic design of the pipes. Prior to considerations of 'modes' or 'keys', we may first discuss more general questions of pipe layout: above all, can we link the material evidence to the scarce literary accounts that offer us dim reflections of the development of harmonic thought before Aristoxenus in the later fourth century? Can we thus establish the general ideas by which the makers of these instruments were guided?

Since the second third of the twentieth century, three conflicting views have been formulated. In 1939, Kathleen Schlesinger argued for a harmonic system that differed entirely from that on which all later sources are based: instead of the concatenated tetrachords of theory with similar internal division, she proposed a musical practice based on equidistant fingerholes and consequently scalar steps that increased with pitch. Schlesinger's theory was never embraced by specialists on ancient music ${ }^{33}$; an a-priori attempt to apply it to the fragmented pipes found in Queen Amanishakheto's tomb at Meroë cannot be reconciled with the evidence ${ }^{34}$.

Martin L. West, starting from his evaluation of the pipes known to him in 1992 and a passage in Aristoxenus, argued that the makers of early auloi typically intended to divide the fourth into intervals of $3 / 4$ tone $-3 / 4$ tone - tone, meaning that they would have first drilled a hole a whole tone below a tetrachord's upper limit and then divided the remainder into two equal parts ${ }^{35}$. The sequence of $3 / 4$ tone $-3 / 4$ tone - tone is indeed mentioned by Aristoxenus as the basis of an earlier aulos-related harmonic system, although it there governs not the distance between fingerholes on an instrument but between different keys (tónoi). However, an analogous hole disposition would arguably form the most plausible motivation for such a scheme ${ }^{36}$.

Most recently, Barnaby Brown has once more proposed a design that does not reflect the scales of theory (or practice, for that matter), but forms a compromise between them: in order to freely modulate between any keys, auletes would have used instruments of an equiheptatonic design, i.e. with fingerholes spaced so as to divide the octave into seven equal steps ${ }^{37}$. In this way, every single interval would need some 'bending' in performance, mostly by manipulating the reed with the lips.

As much as these three interpretational frameworks differ in their conceptual backgrounds, they all need to acknowledge a fundamental, yet disconcerting truth: the fingerholes on the instruments in question divide the fourth into intervals that cannot as such be reconciled with the tenets of ancient harmonic science. And although the earliest extant full accounts of 'legitimate' tetrachordal division are

33 Cfr. Winnington-Ingram 1939; West 1992: 96-97.

34 Bodley 1946; Hagel 2019a.

35 West 1992: 97-101.

${ }^{36}$ Cfr. the reconstruction of the system in Hagel 2000: 177-181; Hagel 2009: 379-390.

37 Brown 2018. 
found in the writings of Aristoxenus, this overarching theorist has certainly not reinvented Greek tonality from scratch. His account is for instance compatible with the numeric divisions given by Archytas more than one generation earlier, and there is every reason to believe that the art of the aulos was in Archytas' focus at least as much as procedures of lyre tuning ${ }^{38}$.

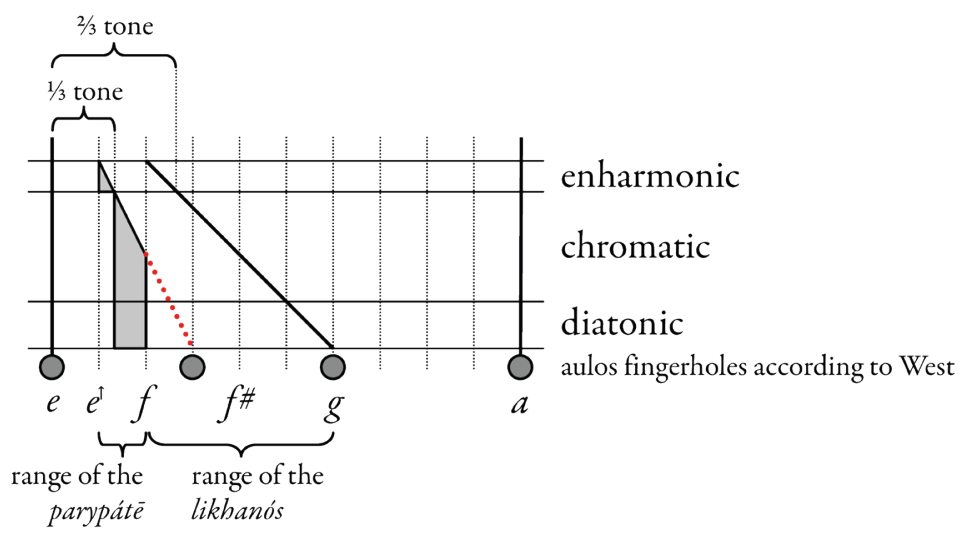

Fig. 8 - Aristoxenus' restrictions for proper Greek tetrachord divisions.

Aristoxenus' approach is laid out in fig. 8, where all admissible tetrachord divisions can be found by moving a ruler between the top and bottom horizontal lines, always keeping it parallel to these. While the bounding notes of the tetrachord to the right and left remain stable, the upper 'moving' note (likhanós) will thus be transferred to any point between a semitone above the lower and a tone below the upper boundary. At the same time, the grey area indicates the respective ranges of admissible lower moving notes (parypátai). According to Aristoxenus, the latter would generally cut the interval between lower boundary and upper moving note in halves (or remain a bit lower) - until they reach a pitch a semitone above the lower boundary, which they must not transgress.

If the rule of interval-halving would apply throughout, allowing the lower moving note to follow the path of the dotted line in fig. 8, it would end up right at the intended placement of the respective fingerhole on the aulos according to West. The tetrachord would thus include a neutral third (halfway between a major and a minor third), an interval familiar from pipe traditions as well as the Near Eastern maqām rast. From the archaeological evidence alone, we would doubtless conclude that the early Greek aulos fitted in squarely with these musical cultures. However, Aristoxenus tells a different story, which is backed both by Archytas' divisions and the evidence from the ancient notational system, which must also predate Aristoxenus ${ }^{39}$. If we are to play

38 Ptol., Harm. 1.13, p. 30.17-31.6 Düring; cfr. Winnington-Ingram 1932; Hagel 2009: 171-182.

39 See e.g. Barker 2016. 
the extant auloi in accordance with these sources, we must always cover a part of that hole in order to play any kind of parypáte. The fully opened hole, in contrast, would play some upper movable note. In Aristoxenus scheme, this note would be chromatic, although of a very narrow type, much narrower than the 'standard' chromatic, which featured a pair of semitones. Indeed the linear arrangement of fig. 8 highlights the considerable lack of symmetry in Aristoxenus' model of tetrachord genera: while enharmonic and diatonic account only for a small part of pitch space, the chromatic covers more than the other two together. I have argued that part of this asymmetry is not so much rooted in ancient musical practice, but owed more to Aristoxenus' predilection for the narrowest possible form of enharmonic, which may have led him to denounce more common forms as basically chromatic ${ }^{40}$. Only in this way, it seems, can we make sense of an earlier account he quotes, where his wording hovers uneasily between the 'semitone' he would like to posit and the three-quartertone interval with which his predecessors had apparently not found any problem ${ }^{41}$. As can easily be gleaned from the figure, according to my interpretation Aristoxenus' squabble would have concerned the difference between two thirds of a tone (his opinion) and three quarters of a tone (perhaps everybody else's?), i.e. no more than a twelfth of a tone (or 17 cents). It is doubtful whether even the best of ancient auletes would have been capable of consistently maintaining so minute a differentiation.

Yet we need to keep in mind that the idea of 3/4-tone intervals, albeit found expressed by ancient musical writers, is a priori at best these writers' interpretation of what the instruments were playing. For all we know, there was no measuring tool that would have allowed them to obtain hard figures for the pitches they heard ${ }^{42}$, and even if there had been such a tool, it would have produced results in terms of length ratios that nobody would have been able to transform to the notion of fractions of a tone, a procedure that requires logarithms.

Conversely, there was no means of precisely transforming the notion of a $3 / 4$-tone interval into measurements for drilling fingerholes. In this respect, the procedures of aulos makers in determining the places where they would set their drills were irrevocably detached from the conceptions of harmonicists talking in terms of fractions of tones - unless perhaps by applying flawed mathematics. Therefore we cannot even hope to obtain the right kind of information from the relevant texts of harmonicist hue ${ }^{43}$. Accordingly we need to extract such information from the instruments themselves.

40 Hagel 2009: 413-429.

41 Ps.-Plut., Mus. 1134f-1135c; cfr. Hagel 2009: 397-407.

42 The monochord was a new invention in the late fourth century; cfr. Creese 2010; Hagel 2012b.

43 Note that while 'Pythagorean'-style ratio mathematics would be adequate for the purpose and was probably used for determining some larger consonant intervals (ps.-Aristot. Probl. 19.23), none of our sources indicates that it may ever have been practically applied in more depth. Archytas figures do not fit the aulos evidence and hardly can be expected to, since he may have associated higher numbers with higher pitch (Hagel 2005: 79), which runs contrary to instrument physics. 


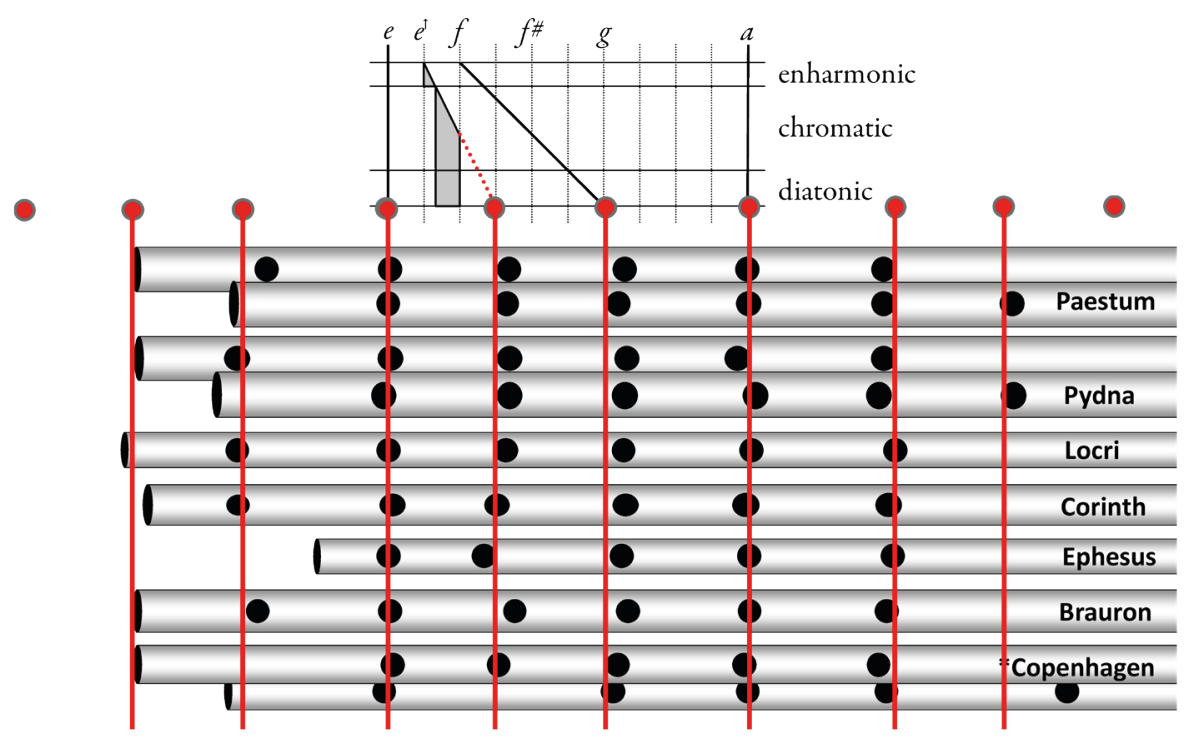

Fig. 9 - Plausible (relative) scales for early Greek pipes and pipe pairs, compared to a scale composed of tetrachords structured as $3 / 4-3 / 4-1$ tones. 'Hole' positions do not correspond to physical distances but indicate intervals on a logarithmic scale: similar distances correspond to similar intervals.

Fortunately, the number of better preserved early aulos pipes is sufficiently large and these are sufficiently consistent for comparing the archaeological evidence with the predictions of the proposed models; by presenting the scales visually, tendencies as well as occasional outliers become evident at once. To make this possible, optimal extensions were determined for the individual finds using the method outlined above. The resulting intervals are printed on a logarithmic scale, aligning the most plausible fourths with the scheme of Aristoxenus' tetrachord divisions. Note that the diagram thus abstracts from considerable differences in instrument size and therefore absolute pitch - for the present purpose, it is only the scalar structure that concerns us. In fig. 9 the interval structures of the relevant finds are contrasted with West's hypothesis, taken at face value ${ }^{44}$. For better comparison, I have extended the tetrachord structure proposed by West by adding further tetrachords of the same type at both ends. As suggested by the data, the lower tetrachord is immediately conjoined, while the upper one starts only after a 'disjunctive' whole tone (two conjunctions would anyway constitute a modulating structure).

44 Calculations rely on data found in Hogarth 1908: 194; Orsi 1917: 101-167; Davidson 1952: 196197; Landels 1963; Olsen 1968; Psaroudakēs 2002; Hagel 2004: 381. For the Copenhagen aulos I have adopted the reasonable reconstruction by Psaroudakēs; the instrument would deserve being dismantled for detailed investigation. I do not include the Reading aulos, which is of very different make and may represent a modern assemblage from ancient parts; the wooden Elgin pipes are excluded for the lack of reliable measurements. 
For all the variation between the individual instruments, in comparison with the literal interpretation of West's division, a systematic error appears to stand out quite clearly: the internal 'movable' notes in the tetrachord are actually higher than predicted, consistently and conspicuously so in the case of the higher one, less conspicuously for the lower, but still consistently with the exception of the pipe from Ephesus. On the other hand, the procedure of combining tetrachords according to ancient precepts predicts many of the other fingerholes quite well, and also some of the notes sounded from the lower ends of the instruments. All in all, an interpretation in terms of tetrachords appears viable, but a conception of $3 / 4$-tone intervals, albeit of ancient pedigree, seems not to do full justice to the data.

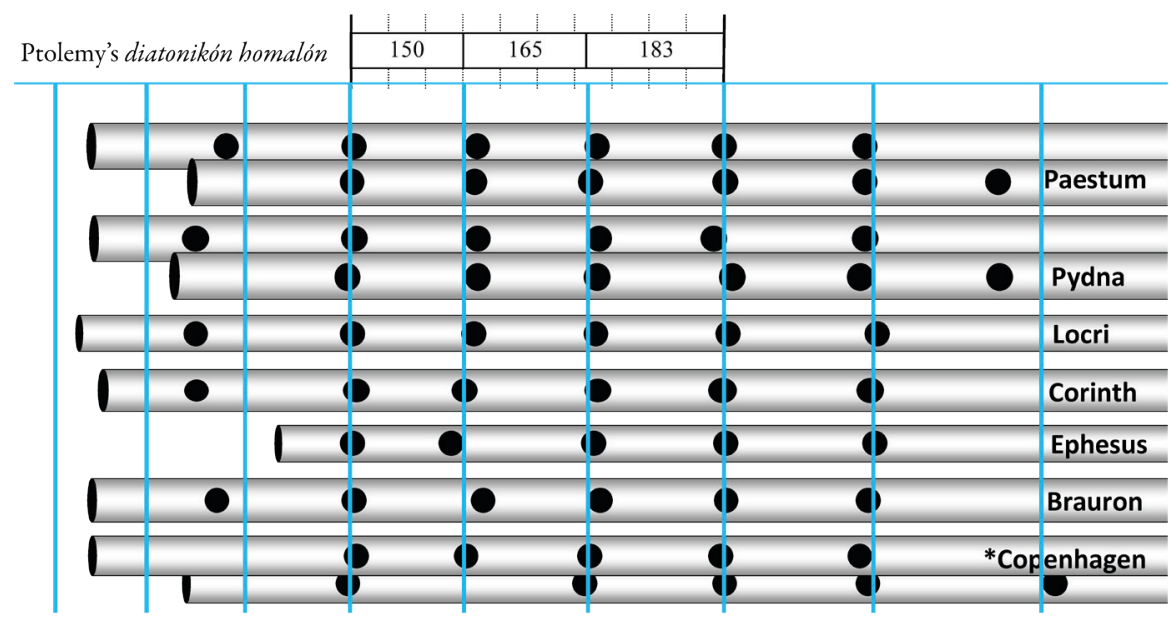

Fig. 10 - Plausible (relative) scales for early Greek pipes and pipe pairs, compared to a scale created from equidistant finger holes.

In fig. 10, the evidence is compared with the predictions from Schlesinger's equidistant model. It becomes immediately obvious that this hypothesis fails completely as soon as one departs from the tetrachord on which the diagram is centred (note however that the interval right above the central fourth is here also a whole tone, just as in fig. 9). On the other hand, within that tetrachord, the equidistant paradigm works significantly better than did the $3 / 4$-tones. We will come back to the implications in a moment.

Before, we need to have a look at Brown's equiheptatonic hypothesis, the interval grid of which is found in fig. 11, once more in comparison with our optimised pipe scales $^{45}$. For most fingerholes, especially in the central region, it works indeed well,

45 It might appear unfair to compare Brown's hypothesis, which involves only impure fifths and fourths, with structures obtained by maximising pure fifths and fourths in addition to octaves. However, the way the optimisation algorithm was applied ensures that it would detect an equiheptatonic setting quite as well. This is 


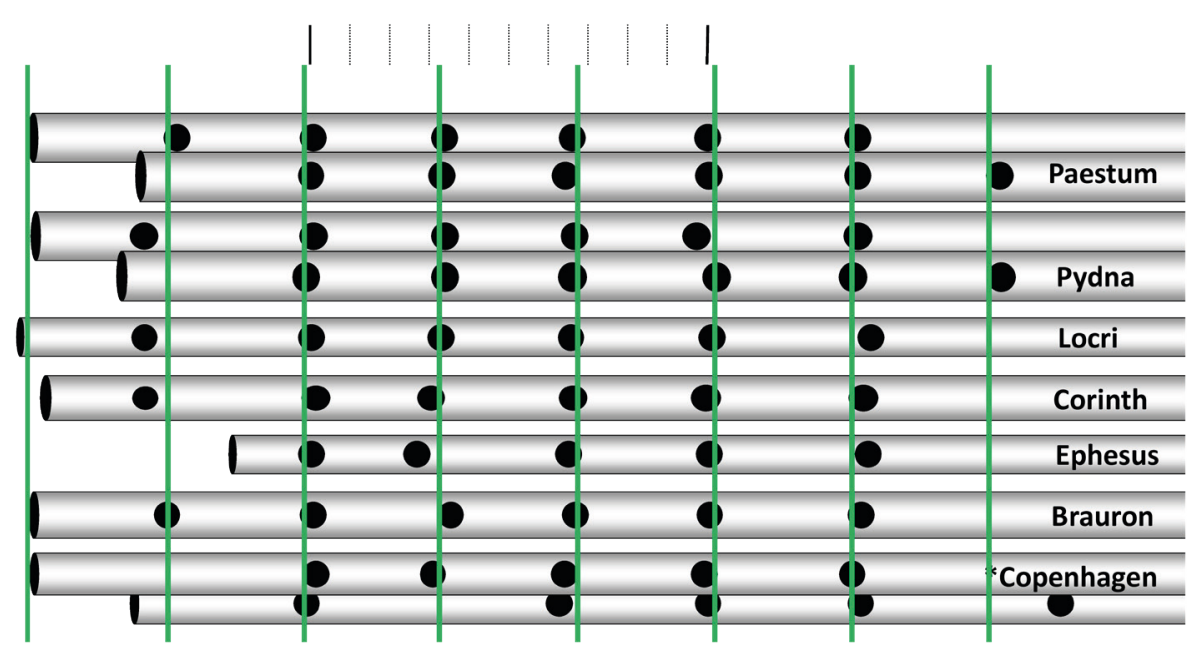

Fig. 11 - Plausible (relative) scales for early Greek pipes and pipe pairs, compared to an equiheptatonic scale.

while conflicts arise mostly for the highest and lowest side holes (the excellent fit for many bass notes from the pipe exits, however, does not distinguish Brown's model from West's, since both share the concept of perfect octaves). On closer inspection of the Pydna and Paestum data, some reasons for doubt emerge. First of all, many of the observed intervals seem closer to pure tuning than would be expected from the hypothesis. Secondly, the exit of the higher pipes does most clearly not follow an equiheptatonic conception but is tuned at a significantly wider interval, forming a rather large fifth with a fingerhole on the lower pipe and diverging from an expected equiheptatonic note by about a sixth of a tone.

All in all, from a purely organological point of view, the benefits of the equiheptatonic hypothesis are hardly significant enough to warrant the assumption of such a radical rift between ancient theoretical models and instrument design at precisely the period when ancient theory developed its key concepts. Since Brown's idea is solely based on his evaluation of the instruments as equiheptatonic, which is not fully borne out by the data, while introducing numerous conceptions into the music of Classical Greece that are never attested in the literary evidence - part of which comes from a period when such instruments were still in use - I cannot see how this hypothesis might possibly escape Occam's razor, quite apart from probably raising more problems than it pretends to solve ${ }^{46}$.

because optimising an equiheptatonic scale consists in establishing compromises between too large fourths and too small fifths, both 16 cents off their perfect counterparts, which is below the applied threshold of 20 cents. As a consequence, Brown could develop his hypothesis while playing on reeds that are based on my optimised values.

46 This is not the place to engage in detailed discussion of various misapprehensions about the ancient sources, and certainly not of those that may distract from the values of Brown's often astute reasoning without doing real damage to the argument (such as apparently mistaking Glaucus of Rhegium for Plato's brother Glaucon?). Here 


\section{An alternative model}

We have seen that the fingerholes of most early auloi are spaced differently enough to exclude Schlesinger's idea of overall equidistance, but neither does their spacing increase uniformly enough down the pipes to bolster the proposition of equiheptatonism. West's model has all the advantages of reflecting ancient textual sources and accounts well for the larger pitch structures, but we have observed that it fell short of describing the nature of their tetrachords with the desired precision. We have, however, also stated that neither ancient theorists nor instrument makers had any means at their disposal to ensure the identity of a 3/4-tone interval, although they might have approximated it by subtracting a whole tone from a fourth and roughly bisecting the remainder. This would have resulted in a good approximation of the division examined in fig. 9, which we have found describes the evidence within the central fourth worse than either equidistance or equiheptatonism. Judging from the currently available evidence, we must admit that the approach that accords best with the texts is not the approach taken by the makers of the examined auloi.

We have further seen that both the equidistant and the equiheptatonic models work better for the central tetrachord. However, while the first still gets its lower intervals somewhat too small, the latter would make the middle one a trifle too large.

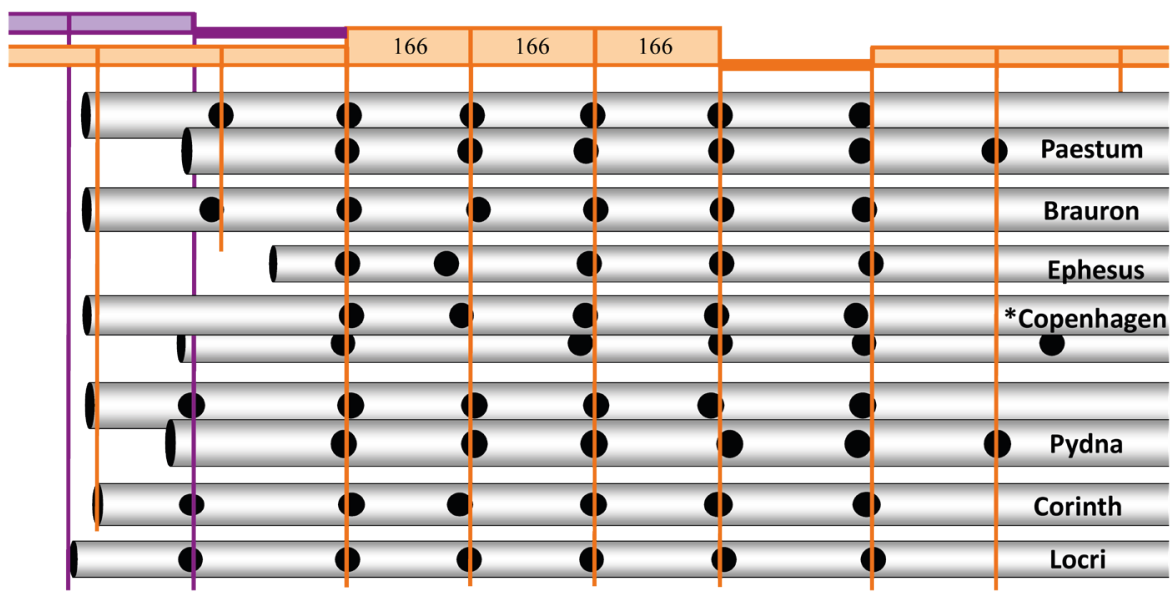

Fig. 12 - Plausible (relative) scales for early Greek pipes and pipe pairs, compared to a scale composed of equally divided tetrachords.

are only two more detrimental points, substituting for many more: how does Brown imagine average citizens, within the brief period of musical schooling in their teens, to have mastered a way of aulos playing he himself, having been a highly professional piper for decades and having spent years on the aulos, confesses still not to master (28)? Or, how could Aristotle possibly take the diesis for the measure in music, if it had been the 21st part of an octave (21) and thus incommensurable with all other concords and, even more obviously, the whole tone, which had been playing a central role in musical reasoning as the difference between a fifth and a fourth? 
The best match is obtained by a sort of compromise between the two approaches, adopting neither a physically equidistant division within the fourth nor a division of the octave in seven equal intervals, but a division of the fourth in three equal intervals, as shown in fig. 12. Such a layout would not be produced by a simple mathematical rule but depend on experience: make the distances between those four fingerholes almost equal, but the lower ones still a bit larger.

What is the advantage of such a division? Firstly, it relaxes the span between middle and ring finger on the higher pipe, as compared to the larger intervals that ancient theory attributes to that space. Ancient theory, that is, with the exception of Ptolemy, who, while keeping the traditional full whole tone in the cithara tuning, maintains that in certain cases the singers would take the note a little bit higher, presumably producing just thirds with other notes of their instrument ${ }^{47}$. Cutting the tetrachord in three roughly equal parts might, secondly, facilitate producing similar intervals.

The notion of three quartertones, finally, which we find in theoretical discussions of aulos scales, may have originated only with the first modulating instruments, the construction of which would doubtless have required certain adjustments; a small enlargement of the highest interval of the tetrachord would probably have sufficed to trigger the notion of its structure as a high tone plus twice half of the rest, leading to the notion of three quarter tones, where precise measurements were unattainable.

\section{Tetrachordal structures}

Starting from an equal division of the fourth, we may tentatively interpret the remaining fingerholes in terms of tetrachordal structures. Above what we have posited to form a kind of 'central' tetrachord, we always seem to find, not another tetrachord in 'conjunction', but a 'disjunctive' whole tone. This would lead to the highest note of some pipes, while the higher members of a pair adds another interval, which may be interpreted as the lowest member of another, truncated tetrachord. The highest note of the Copenhagen pair stands out once more, fitting this scheme no better than any other.

Below the central tetrachord, matters are more complex ${ }^{48}$. On some pipes, such as the Brauron and the lower member of the Paestum pair, the adjacent intervals are similar to those above, suggesting another tetrachord being conjoined. On others, including Pydna, Locri, Corinth and the higher pipes from Paestum and Copenhagen, the interval below the central tetrachord is clearly larger than those within it and thus calls for classification as another disjunctive tone. Below it, we would then expect the start of one more tetrachord.

47 Ptol., Harm. 1.16, p. 39.12-17 Düring; cfr. Hagel 2009: 211-212.

48 When dealing with the other proposed models, we could evade discussion of the variance at that point: Schlesinger's and Brown's hypotheses have no room for such variance, and in West's theory, the notes in question happen to fall together, the highest note in the tetrachord being of the same size as the 'disjunctive' tone. 
In a regular scale, it might be objected, disjunctive tones cannot stand on both sides of a tetrachord; in order to complete the octave and create continuous non-modulating scales, two conjoined tetrachords need to stand on each side of a disjunctive tone. However, in the earliest Greek scalar structures of which we have an explicit account, deviation from this rule is common. The scales in question are the 'barmoniai' reported by Aristides Quintilianus, believed most probably to rely on some work by Aristoxenus ${ }^{49}$. Being in principle enharmonic, they nevertheless incorporate additional whole tones (cf. fig. 13 below). Indeed Aristides' Dorian and Phrygian each entertain a tetrachord with a disjunctive tone on either end, while his Mixolydian includes a tone below a note as an alternative to a full enharmonic tetrachord running down from the same note; in his Iastian, finally, a similar tone is found within an empty fourth, once more as part of an otherwise enharmonic scale.

A comparable combination of conjunct tetrachord and disjunctive tone below a note may be observed on the instruments from Pydna and probably also Copenhagen. On the Pydna aulos, the lowest side hole of its lower pipe and perhaps the exit of the higher would play the disjunctive tone; but when the side hole is plugged, the exit of the lower pipe will play a fourth below the small finger hole of the higher pipe, as if it were part of a conjoint tetrachord. The Corinth fragment would fit in a similar category, but a confirmation would require evaluating the missing second pipe. The Paestum aulos, in contrast, would play the disjunctive tone only as the exit of the higher pipe, with its lowest side hole plugged, while either of the corresponding alternate holes on the lower pipe would form part of a conjunct tetrachord. It seems that Paestum and Pydna provide access to a very similar pitch structure, but distribute it in a different way, with potentially considerable effects on what may be performed.

\section{Pitch and notation}

I have mentioned the comparatively small pitch difference of slightly less than a semitone between the Paestum and the Pydna instrument above. In order to include fragmentary or differently structured instruments in the comparison, we need to define a reference point. Different scales can be related to each other by comparing the interval between (functionally) similar notes, such as most prominently the mésé, 'central note', defined as the note below the disjunctive tone. This approach will be most convenient for the present purpose, not least because it allows to ascribe a meaningful value to pipes that have survived without their counterpart, regardless whether they have been the lower or the higher member of the pair. The 'disjunction' in question is of course the ubiquitous one above our 'central tetrachord', not the

49 Aristid. Quint. 1.9, p. 18-20; cfr. Barker 1989: 419, n. 112; Barker 2007: 45-48; Hagel 2009: 18-19, 390-393. 
whole tone that is found below it on some pipes. Similarly, where there are two potential disjunctive tones in Aristides' scales, the mésé is always defined by the higher one. In this way our 'central tetrachord' becomes identical with the ancient tetrákbordon mesôn. The following table details the respective pitches of all the instruments investigated above ${ }^{50}$ :

\begin{tabular}{lcl}
\hline & mésē inHz & modern note \\
\hline Locri & 262.5 & $\mathrm{C} 4+5$ \\
Brauron & 295.5 & $\mathrm{D} 4+10$ \\
Corinth & 295.5 & $\mathrm{D} 4+10$ \\
Pydna & 296.0 & $\mathrm{D} 4+10$ \\
Paestum & 310.5 & $\mathrm{D} \sharp 4$ \\
Copenhagen & 327.5 & $\mathrm{E} 4-10$ \\
Ephesus & 573.5 & $\mathrm{D} 5-40$ \\
\hline
\end{tabular}

Apart from the tiny pipe from Ephesus, which sounded an octave higher than the rest, the pitches of the instruments vary within a range of no more than a major third. Three of them, the Pydna pair along with the pipes from Brauron and Corinth, obtain their optimal tuning at an identical pitch, which is located just in the middle of that range. Might their shared provenience from the Greek mainland testify to a more narrowly defined pitch standard for instruments of the same class there? At any rate, the correspondence is too precise to be accidental. In fact, a combination of the higher Pydna pipe with those from Corinth or Brauron would play just as well as the genuine Pydna instrument.

I have argued that pitch became an integral part of the concept of key (tónos, trópos) developing from mode when modulating instruments were conceived and the system of musical notation acquired the ability to express the required modulations by using different notes for the mésai of various keys. Before that, notation would only have expressed patterns of tetrachords. If our instruments, the earlier of which quite likely precede that development, belong to the earlier stage, one would expect that the notes from the open holes of the Pydna and Paestum types were most probably written as follows, equating what we have defined as their likely mésē with $\mathrm{K}<$ (which later became the mése of the central Lydian key ${ }^{51}$ :

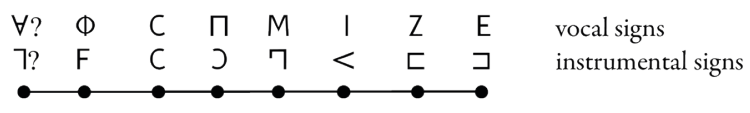

50 The Elgin aulos may belong to the same type, with a mésē of about $272 \mathrm{~Hz}$. After an addition of perhaps $3 \mathrm{~cm}$ for the lost necks below its bulbs and another $3 \mathrm{~cm}$ for the inserts, it would still call for exceptionally long reeds of about $10 \mathrm{~cm}$ length.

51 On the primacy of the Lydian tónos within modulating notation cfr. Hagel 2009: 9-98. 
Such an interpretation of the pipes' scales is especially enticing because it matches the Vienna Orestes papyrus so nicely, our oldest fragment of readable European music ${ }^{52}$. In this way we could play its melody, which moves precisely between $\Phi$ and $\mathrm{E}$, on a reproduction of a contemporary instrument. It is true, one needs to switch the melody between the higher and the lower pipe, but facing a range of a ninth this would hardly be avoidable on a doublepipe of any suitable pitch range.

Unfortunately this straightforward interpretation faces serious problems. Most importantly, the papyrus presents some additional notation that is generally interpreted as consisting of 'instrumental' note signs as opposed to the 'vocal' signs used for the song line. These include 7 , which might be identified with the bass note of our instruments, but also $\mathrm{Z}$, which would then exceed its treble note by a tone. If the identification as instrumental signs holds at all - to the best of my knowledge, no convincing alternative has been suggested so far - these would naturally be stronger candidates for aulos notes than are those of the voice. But they span more than an octave and therefore more than any of the instruments surveyed here might have played ${ }^{53}$.

Is there anything to be learned from the actual pitch of the instruments, given that keys were later defined in this way? All we know about later Greek music suggests a pitch standard of $\mathrm{I}<\sim 245 \mathrm{~Hz}^{54}$, a minor third below the favoured mése of our instruments around $295.5 \mathrm{~Hz}$. In turn, these mésai would suggest the key that the Roman-Imperial period knew under the name of Hyperphrygian, and which had earlier been known as Hypermixolydian, a scale seemingly introduced only by Aristoxenus. From the viewpoint of keys as relative pitches, therefore, the instruments just do not make any sense. We might easily dispose of such concerns by appealing to the notion of transposing instruments, which is bolstered by the observed variance in pitch with other, similarly structured pipes - were it not for the fact that the 295.5-Hertz instruments seem to abide by the later pitch standard in a very different way: their total range is precisely the range of the ancient lyre. The bass notes from Pydna, Brauron and Corinth coincide with the lyre's bypáte CC, exactly like those of the Louvre aulos. The pipes from Brauron and Corinth were almost certainly the longer members of their respective pairs, as is indicated not only by the musical similarity with the longer of the Pydna pipes, but also by the placement of their thumbholes, which are displaced towards the left, making them left-hand pipes (or at any rate aligning them with the longer pipes from Pydna and Paestum, which also have left-displaced thumb holes). Thus we do not know the treble note of the original instruments to which the fragments from Brauron and Corinth belonged; if they were of the same type as the extant pairs, with a shift of one fingerhole between the ranges of left and right hand, it would stand one scalar

52 PVienna G2315 = Pöhlmann and West 2001: no. 3.

53 Note that extending the instrumental range by overblowing is no option either: since cylindrical pipes overblow to the twelfth, the ninth that the instrumental signs seem to demand is still unavailable.

${ }^{54}$ For questions of absolute pitch cfr. Hagel 2009: 68-96. 
step above their highest fingerhole $U Z$. Such is the case on the Pydna pair, and the note in question is identical with the lyre nété $\theta$ 丩. The same treble note is later found on an instrument from Pompeii.

Were these instruments therefore designed specifically to play together with the

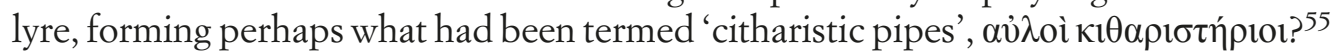
Again, the answer seems to be negative. All reliable sources on lyre tuning include the interval of a tone between the central string, mésé, and its higher neighbour, paramése $\bar{e}^{-56}$. When the ps.-Aristotelian Problems contemplate a sequence of two conjunct tetrachords as a possible alternative for the tuning of a seven-stringed lyre, this is clearly introduced as mere speculation, and cannot have been more when being incorporated into Nicomachus' fictional history of the lyre ${ }^{57}$. At any rate, none of the two options fits the design of our auloi. The seven-note conjunct hypothesis falls short of their treble note, apart from running into hardly surmountable problems to accommodate the sequence of intervals on the pipes as tetrachords, while the wellattested octave tuning depends on having the disjunction two steps further down than we find it on the pipes.

Even so, the perfect agreement of so many independent sets of data - three of the instruments investigated here, those from Pompeii and the Louvre, cithara and lyra string lengths - at least points to a well-defined treble pitch (nété) from quite early times on.

\section{The question of harmonía and êthos}

If our instruments refuse to form the single puzzle piece that would complement our picture of Greek music from the Classical period, we ought to remember the fallacies of archaeological bias. Even if all the (few) preserved bone instruments appear to represent perhaps two closely related types of instrument, should we believe that the innumerable perished wooden doublepipes were all of a similar design? On the Louvre aulos, albeit certainly of a significantly later date, the highest holes of the two pipes were three steps apart, as opposed to the single step on the instruments investigated here. Extant Egyptian doublepipes exhibit a difference of two steps ${ }^{58}$, and I have hypothetically reconstructed a 'Dorian' aulos with a difference of two fingerholes from Aristoxenus' remarks on traditional aulos music ${ }^{59}$ - a prediction that annoyingly fails to be borne out by the archaeology. The oldest system that integrated different modes for the purpose of producing modulating auloi placed their highest notes only a minor third above Lydian mésé, on a pitch notated in different contexts

55 Ath. 634ef; cfr. also 176ef; Pollux 4.81.

56 Starting from Philolaus fr. 6a up until Ptolemy's Harmonics; cfr. Hagel 2009: 112-113.

57 Ps.-Arist. Pr. 10.7; Nicom., Ench. 3, p. 2 42.4-7 Jan; 5, p. 245.14-18.

58 E.g. the instrument preserved in the Berlin Egyptian Musem inv. ÄM20662/20663.

59 Hagel 2009: 408-409. 
either as $\mathrm{E} \sqcup$ or $\Gamma \mathrm{N}$. This calls for a remarkable finger span, not easily available to an average modern adult hand. If the other pair of such a pipe stood at an even lower pitch, the required span would border on the unmanageable. Possibly, therefore, that inferred treble note actually refers to the melodic pipe of a pair, while other pipe would have been conceived as providing the accompaniment (kroûsis), standing at a higher pitch ${ }^{60}$. The interval between the two treble notes may have been different on different instruments; some may have entertained the traditional lyre nêtée, implying a difference of two steps between the pipes. All this must at present remain speculation; in our context it deserved mentioning only in order to enlarge our perspective from the few finds under investigation to the full extent of the unknown and perhaps still to be discovered.

Anyway, given the early date of some of our instruments, we cannot expect that they would fit into a pitch-aware scheme of interconnected modes, which was almost certainly not developed before the later fifth century BC. So at present our only option might be to relate the instruments to the shapes of Aristides' scales, which he reckons were older than Plato, and whose designation as harmoníai distinguishes their modal character nicely from the indiscriminate notational keys (tónoi) into which they ultimately developed. Fig. 13 illustrates their structures, in terms of the quartertone enharmonic by which Aristides describes them. However, he also states that, in very old times, musicians had played them using tetrachord divisions unlike any of the Aristoxenian standard he had listed before. I have argued that this may well refer to the wider enharmonic which Aristoxenus downplays so successfully ${ }^{61}$. We might now add the unusual diatonic that the early pipes would have played, with an upper interval significantly smaller than the whole tone which Aristoxenus prescribes as the smallest interval permitted in that position (cf. fig. 9: the difference amounts to about the sixth part of a tone). In this context, we also need to acknowledge that the enharmonic character of Aristides' scales can only be an incomplete guide to aulos fingerholes. The instrument, respecting the shape of the human hand, must always have included holes for the diatonic notes just as well; fig. 13 indicates their position as faint circles $^{62}$.

Above we have established the scale of the Paestum and Pydna instruments as most likely structured in the way of 'two steps - tetrachord - whole tone - lowest interval of a tetrachord', with variance in the structuring of the lowest two steps. At any rate, the bass notes of each pipe would only be available when plugging the lowest side hole of the lower pipe; in 'normal' playing mode, therefore, the difference affects only one note, which the Pydna aulos has a whole tone below the tetrachord, while that from Paestum makes it a tetrachordal interval (in terms of ancient theory, a kind of diátonos bypatôn, although pitched higher than Aristoxenus would have allowed). In

${ }^{60}$ For a criticism of the widespread notion of ancient accompaniment always being above the melody cfr. West 1992: 206, n. 41, even though this is the case for all accompanying notes listed by Aristox. ap. ps.-Plut. 1137b-d; cfr. West (1992) 359, n. 13; Barker 1995: 50; Hagel 2004: 378; Hagel 2009: 407-411.

${ }^{61}$ Hagel 2009: 391-392.

${ }^{62}$ Cfr. Hagel 2009: 393-394. 
Fig. 13 - A structural view of the Pydna and Paestum auloi alongside the old harmoniai transmitted by Aristides Quintilianus, with hypothetical original notation; cfr. Hagel (2009) 370 Diagram 89.

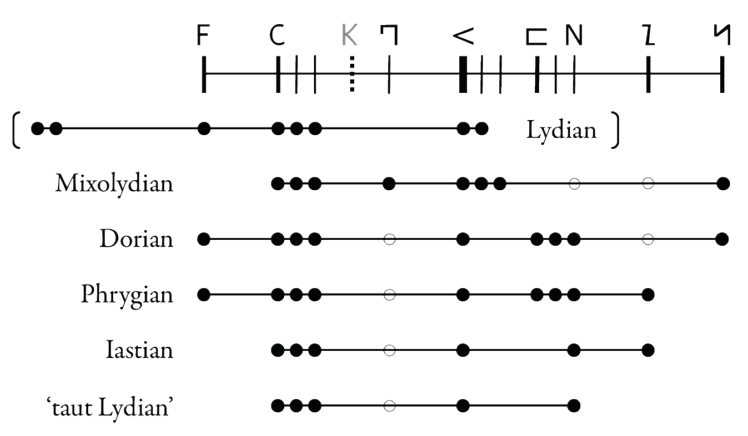

Pydna

Paestum

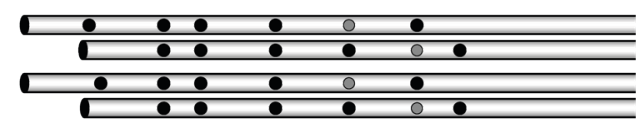

fig. 13, their structure is shown 'Aristoxeanised', permitting a direct comparison with the harmoniai. It becomes evident that, given the apparent position of the tetrachord on the pipes, these cannot have accommodated most of the latter, stopping short of the highest notes of Dorian, Phrygian, Mixolydian, and even the significantly smaller compass of Iastian. The regular enharmonic octave species that Aristides lists under the name of Lydian mainly extends downwards from its complete tetrachord and therefore cannot fit either; also, the 'quartertones' on either end of it raise doubts whether an aulos can conceivably play a scale of precisely this form ${ }^{63}$. It is only the smallest scale, the so-called 'taut Lydian', that the instruments appear perfectly accommodated for. In fact, the entire 'taut Lydian' scale can be played on the higher pipes, so that the lower ones might consistently be reserved for the accompaniment ${ }^{64}$. From a purely structural perspective, the odds thus point towards Aristides' 'taut Lydian', if there shall be any hope at all to retrieve information pertaining to this type of pipes from our texts.

Aristides' list refers to Plato's Republic. It is most likely derived from a much earlier source, most probably a work by Aristoxenus, that specified precisely the modes discussed in Plato's famous text. The implications are that whoever compiled it first would have thought that scales of much this form were current in Plato's lifetime - and, if we trust Aristides' wording, even earlier. This assumption finds confirmation in my reconstructions of pre-Aristoxenian modulating systems, which must have been based on harmoniai very much like those found in Aristides ${ }^{65}$. On balance, we would expect that these pitch structures played an important role in

63 Cfr. however Brown 2018: 22, who would achieve this by embouchure.

${ }^{64}$ Cfr. Hagel 2009: 395-396; the 'Syntonolydian' pipe constructed there (Diagram 96) is almost identical with the higher pipes from Pydna or Paestum; note its close correspondence with iconographical measurements.

${ }^{65}$ Cfr. n. 36 above. 
Greek music around 400BC. On the other hand, we have established a type of instrument that was in use during Plato's lifetime, enjoyed a wide geographical distribution, a significant tradition, and had developed an astounding degree of standardisation at least in mainland Greece. Should we really assume that the instrument type that features most prominently in the archaeological record did not form part of the musical mainstream reviewed by Socrates and Glaucon in the Republic, or among the scales that musicians and instrument makers endeavoured to integrate with each other?

If we are inclined to assume that our instruments belonged to the sphere of music that Plato's Socrates was interested in, and if our tentative identification of their scale should hit upon the truth, what does this imply for these instruments' place in society? 'Taut-Lydian', we are told by Glaucon, belongs to the plaintive harmoniai, along with Mixolydian and 'some others of that kind'. Accordingly, I might now point out how appropriately such instruments would have been placed in graves, that this would have caused an archaeological bias which explains their prevalence in the record, and leave it at that.

However, we ought not lightly gloss over some significant problems concerning the identity of those scales that share the name of 'Lydian'. In the Republic, Glaucon mentions 'Lydian' and 'Iastian' as the relaxed scales, adding an indefinite pronoun that hovers between admitting his lack of detailed knowledge and suggesting more than one type of either:

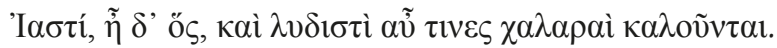

Some Iastian and Lydian, he said, are called slack.

(Plato, Rep. 398e)

This unqualified 'Lydian' contrasts with the 'taut Lydian', for which Plato uses the compound syntonolydistí, placing it among the plaintive modes. Aristides refers

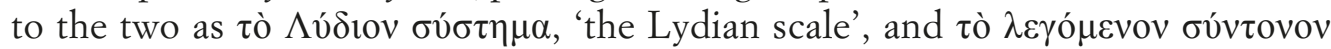
$\lambda v$ $\delta$ เov, 'the so-called taut Lydian'. From Plato alone it must therefore appear that Lydian was typically the relaxed variant. This would agree with the perception of the Lydians as relaxed people given to feasting and luxury, while at the same time evoking the musical notions of relaxed as low and taut as high pitch, notions obtained for example from the experience of tuning strings. However, ancient music history clearly disagrees with the classification we get from combining Aristides with Plato. The later form of the Lydian octave species as well as the place of the Lydian in the system of keys are based on a scale that looked like Aristides' 'taut Lydian', while his unqualified Lydian ended up as the 'Hypolydian' of later systems ${ }^{66}$. Musicians, it seems, have regarded Aristides' 'taut' variant as the Lydian scale per se.

66 Winnington-Ingram 1936: 21-30; West 1992: 227-228; Hagel 2009: 34-35. 
On top of this, one Roman-period source claims to know the origin of the slack variant:

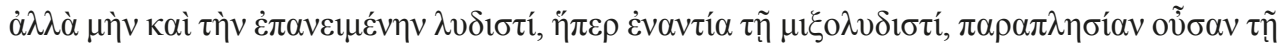

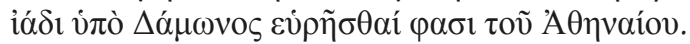

And it is also said that the relaxed Lydian (the one that is the reverse of Mixolydian), which is similar to Iastian, was invented by Damon of Athens.

(Ps.-Plut., Mus. 1136e)

The text continues with an explicit reference to the Republic, whose terminology it has however subverted by bestowing a qualifying adjective to 'the relaxed Lydian', as if that would have been its name. The alleged similarity to Iastian is puzzling and one might only explain it as a reference to their similar character in Plato from the shape of the scales, as found in Aristides, Iastian contrarily resembles the 'taut Lydian'. The definition as 'the reverse of Mixolydian' - for which see below betrays a source with more detailed harmonicist knowledge. This ought to caution us from dismissing the supposed attribution of what Plato calls 'Lydian' to Damon all too lightly. But if we give it any credit at all, it corroborates our conclusion that the more typical 'Lydian' was in fact Plato's 'Taut-Lydian'. Taken at face value, it would reduce the 'slack' variant and with it the origin of Hypolydian to the status of a creation of Classical Athens with no true Lydian pedigree. But Lydian as a mode was of course older, and so were Lydian auloi; Pindar mentions both as constituents of his own music ${ }^{67}$.

At any rate, the harmonicist tradition, which derives the 'Lydian' tónos and the 'Lydian' octave species from Aristides' 'taut Lydian', thereby encourages us to remove the qualification from our instruments, making them just 'Lydian'. What does this imply for their cultural status? Contrary to Glaucon's classification of 'Taut-Lydian', it does not seem plausible that Pindar would have clothed his victory odes in tearful music. Something must have gone wrong here. One might perhaps be tempted to reject Glaucon's account on the grounds that Plato himself has taken pains to portray his figures as only superficially acquainted with musical matters. Indeed Aristotle points out that Socrates' admission of the Phrygian mode on the basis of its characterisation by Glaucon was hardly compatible with common views and the mode's actual cultural significance ${ }^{68}$. However, while he does not mention anything such as a 'taut' variant of Lydian, Aristotle plainly confirms that 'Lydian' belongs to the relaxed harmoniai, while siding with those musical experts who maintain its educational value against Plato's Socrates ${ }^{69}$.

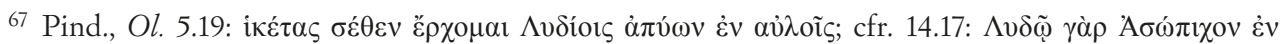

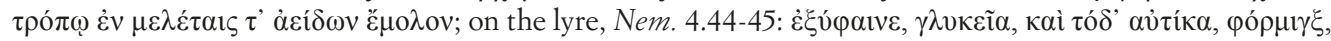

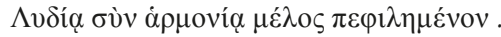

68 Aristot. Pol. 1342a; cfr. Hagel 2019b; on Plato's possible motivation, also Lynch 2017.

69 Aristot. Pol. 1342b. 
In this way, Aristotle helps us pinpoint the contradiction in the sources. When he composed his Politics - and almost certainly already when Plato wrote the Republic - the two rivalling schemes of keys which Aristoxenus ridicules must already have been in place. Both incorporated a single 'Lydian' (and not even a 'Hypolydian'), which was based on a scale resembling Aristides' 'taut Lydian'. But it cannot have been recognised as 'taut Lydian', if the only Lydian Aristotle knows was perceived as a slack mode. What seems to be wrong is the association between the Lydian scale form and the designation 'taut Lydian', which we find only in Aristides.

If we would exchange the names between the two Lydian scales, much everything else would work out, and Plato's and Aristotle's words would stand reconciled with what we infer about the musical systems of their times. Such a confusion would probably have originated long before Aristides, as it also seems to underlie the passage that ascribes the relaxed Lydian to Damon. We may even speculate how it might have arisen in the first place. Anybody who was aware that the two scales corresponded to Lydian and Hypolydian in all systems of keys at least from Aristoxenus on, might have easily misconstrued their relation. In the typical diagram of tónoi, they appear as similar scales set to different pitches. The Hypolydian stands a fourth lower than the Lydian, which might prompt 'correcting' their respective identification with the Platonic harmoniai: as the higher tónos, only Lydian would appear to qualify for the role of 'Taut-Lydian', while Hypolydian would naturally be perceived as the relaxed variant. In Plato's times, no diagrams of that kind had yet been devised; in those that existed, the highest note of Lydian coincided with those of the other modes. Consequently, a perception of relative slackness or tautness would have relied on different criteria - such as the preponderance of lower or higher notes in the characteristic melodies, or perhaps the typical sizes of more traditional instruments ${ }^{70}$.

Nevertheless, postulating the switch of two labels in the course of the tradition is a bold move, even when the sources appear to contradic each other, and do so independently of how we interpret our instruments. There may be an alternative; no less speculative, perhaps, but more conservative regarding the reading of the sources. At least, it challenges them only at a point that was criticised by none lesser than Aristoxenus himself. As mentioned above, auloi included not only fingerholes for playing in enharmonic, but also diatonic notes. However, Aristides' harmoniai are purely enharmonic, with the exception of some irregular notes. We may seek the reason for that not only in the music that was played in the period, but in a restriction of theoretical endeavours that Aristoxenus duly criticises ${ }^{71}$. Indeed, diatonic aulos music must have been commonly used - even before Aristoxenus, musical authorities

${ }^{70}$ Note also that on the lyre, a tuning in the Hypolydian key was indeed tauter than a Lydian tuning, since it required tightening one string (i.e. parypátē from Lydian $\mathrm{P} \cup=f$ to Hypolydian 'khrōmatikể, $O K=f \#)$.

71 Aristox., Harm. 1.2, p. 6,6-19 Da Rios; cfr. Hagel 2009: 375-377. 
had naturally conceived the invention of the relatively young enharmonic on a typical aulos to have started from diatonic ${ }^{72}$. In a different context, Aristoxenus expressed the view that Phrygian is best suited for the diatonic, just as Dorian is for enharmonic ${ }^{73}$, but nevertheless Aristides' variant of the Phrygian scale is as much enharmonic as it might be.

But diatonic variants may have circulated in musical writings, representing large parts of musical reality better than the shapes reported by Aristides. The passage about Damon's alleged invention of the 'Relaxed Lydian' may prove just as much ${ }^{74}$. When introducing the notion of 'Relaxed Lydian', the (original) author was obviously not confident that every reader would be able to establish its identity. Consequently he defined it as 'the reverse/opposite of Mixolydian', in what he apparently thought would provide an unequivocal reference. It does however not seem possible to establish how Aristides' 'Lydian' (or any similar scale) might be the reverse of any form of Mixolydian - unless one looks at their diatonic shapes.

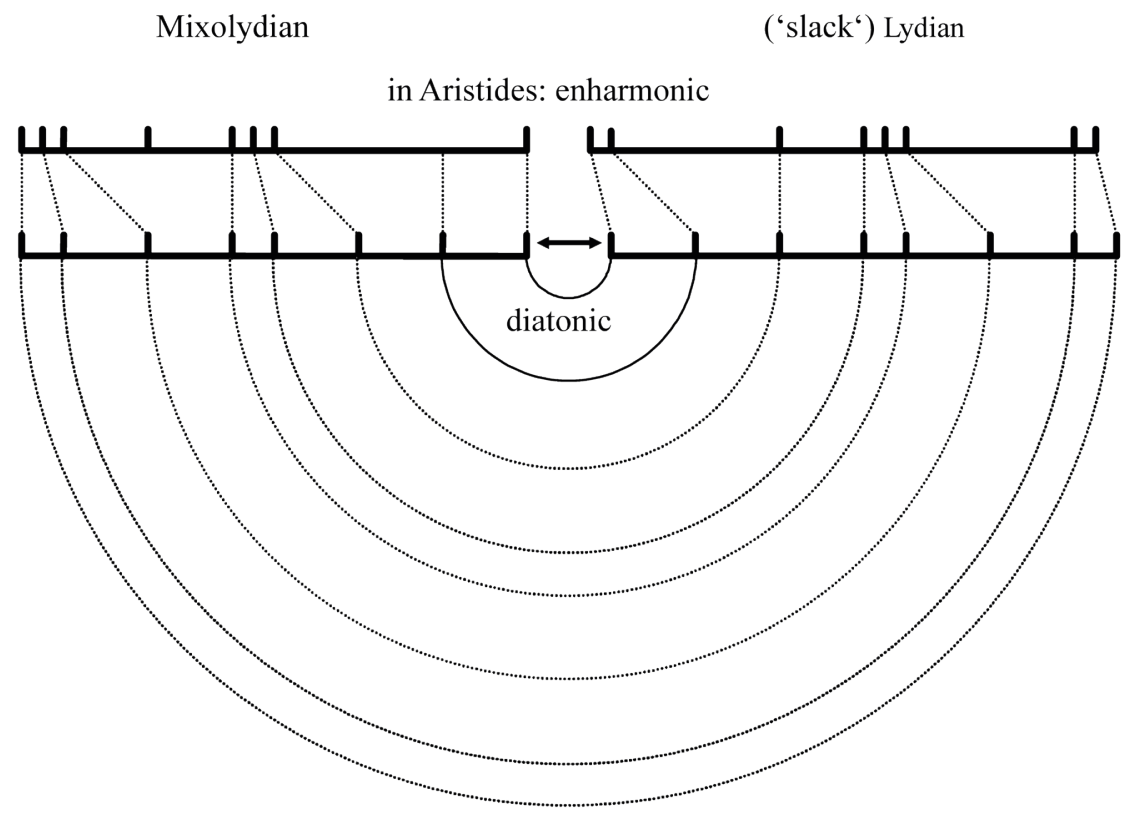

Fig. 14 - An interpretation of 'Slack Lydian' as reverse Mixolydian in Ps.-Plut., Mus. 1136e.

72 Cfr. n. 41 above.

73 Aristox. ap. Clem., Strom. 6.11.88.1.

${ }^{74}$ Cfr. Hagel 2000: 177-178. 
In diatonic, both scales still encompass exactly an octave; Mixolydian also becomes identical with the octave species of the same name, since its irregular note falls together with the diatonic note in the lower tetrachord. In addition, the missing note a tone below its upper end needs to be supplied, which conforms with a reanalysis of this scale that is mentioned in the sources ${ }^{75}$. As can be gleaned from fig. 14, 'Slack Lydian' is now indeed the reverse of Mixolydian regarding the succession of tones and semitones.

We are not absolutely certain from which source the author of the dialogue quoted the passage in question, but from the context it appears to be taken from a work on the history of harmonics by Aristoxenus, which would account for the technical language no less than for the interest in interval sequences. This entails that Aristoxenus, when dealing with music history in the fifth century BC and specifically with Damon, would not only find it most natural to refer to diatonic scale forms, but also expect his readers to anticipate a diatonic context. At any rate, the 'Slack Lydian', being defined in this way, can only be a diatonic scale.

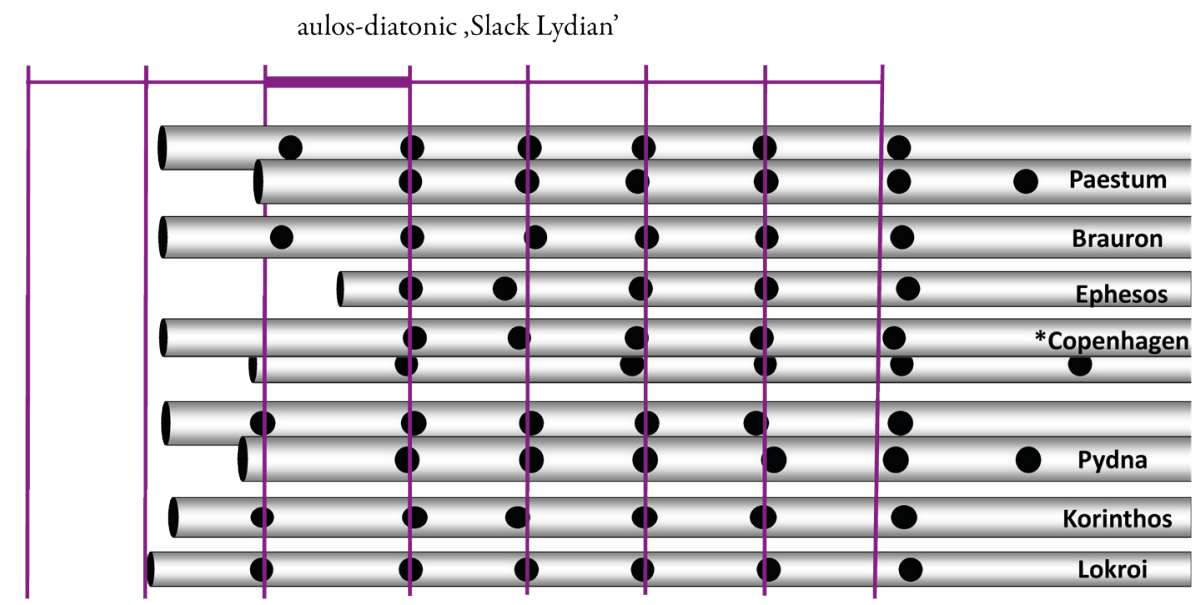

Fig. 15 - Diatonic 'Slack Lydian' and plausible (relative) scales for early Greek pipes and pipe pairs.

As such, it might finally stand chances of relating to our instruments. In contrast to ('Taut') Lydian, the disjunctive tone of 'Slack Lydian' sits below its central tetrachord, above which we find once more the lowest interval of the next tetrachord, while there are two more steps at the lower end of the pipe. As we have seen above, some of the extant instruments indeed include a whole tone below their central tetrachord, if only as an alternative. In this way, the left-hand pipes from Pydna, Corinth and Locri can incorporate almost the entire 'Slack Lydian' scale. Their highest interval is of course too large, but the fingerhole in question would anyway require half-covering, in order to produce the half tone of

75 Ps.-Plut., Mus. 1136de; cfr. West 1981: 127; Barker 2007: 49-50; Hagel 2009: 372-373. 
a regular diatonic scale. Still, the lowest interval is conspicuously absent, and the lowest existing note is only available when the lowest side hole on the lower pipe is plugged. Consequently, the next note would have to be supplied from the higher pipe, entailing the plugging of its lowest side hole as well. Interestingly, with both these holes plugged, the same scale is even available on the Paestum aulos, the exit of whose higher pipe produces the required pitch, in contrast to its 'equivalent' side hole on the lower pipe.

The present hypothesis would have the substantial advantage of incorporating both 'Lydian' scales on a single Lydian instrument. But can it overcome the lack of the lowest note? The answer to this may depend on factors about which we still have only limited knowledge, especially the relation of the other scales in Aristides to actual instruments. The full Dorian scale of a ninth, for instance, cannot even have been playable on an aulos with a shift of two fingerholes between its pipes without the help of some kind of mechanism. Since the instrument type under scrutiny predates the invention of mechanisms - sliders are not attested for the Classical period and turning sleeves not until centuries later - it follows that an early Dorian instrument, whatever its design, would have fallen short of the Dorian scale in Aristides. Similarly, it would be no great surprise if an early 'Slack Lydian' of more limited compass would later have been complemented to the regular octave species which Aristides attests in enharmonic shape, while the passage from pseudo-Plutarch apparently presupposes the diatonic counterpart.

At any rate, the present hypothesis would enable us to uphold both Plato's and Aristides' accounts, while explaining the designations that are found in our sources as well as their fate throughout the development of tónoi systems and notation. The two 'modes' would have started as two different ways of using the same pair of pipes. One focused melodically on the high pipe, producing what Plato knew as 'Taut-Lydian'. The other realised the melody mainly on the low pipe, although probably including the bass note of the other pipe, and in addition plugged both normal bass notes in order to gain access to the even lower notes from the exits of the pipes. Accordingly, this was perceived as the 'relaxed' mode. Damon may have been responsible for some changes in using this configuration, but will hardly have invented the entire thing. Might it however be significant that our earliest examples from Brauron and Paestum do not include the disjunctive tone of 'Slack Lydian' on the lower pipes, while Locri, Corinth and Pydna, none of which necessarily predate Damon's active life, do?

When the Lydian aulos was incorporated within modulating diagrams and instruments, it was naturally the treble note of its higher pipe which was equated with the highest notes of other modes, so that none of the two ways of playing 'Lydian' was excluded. For this reason, the 'slack' variant did not surface in the two reconstructed old schemes. Its interval configuration re-emerged as Hypolydian in Aristoxenus' substantial refurbishment. Its position a fourth beneath Lydian now systematically complemented the relationship between Dorian and Hypodorian as well as Phrygian and Hypophrygian. However, their musical relation was different from that between 
'slack' and 'Taut Lydian' on the old Lydian pipes ${ }^{76}$, and indeed no source draws a line between the concepts of 'Slack Lydian' and Hypolydian.

However we try to resolve the conundrum created by Aristides' identification of Plato's names, the instruments whose musical potential we have been investigating, are most probably typical Lydian auloi, quite possibly just of the sort Pindar speaks of. Victory odes, of course, have their place in a celebration - which is ultimately a celebration between peers, just as Pindar likes to stylise himself as a peer offering his music as a gift. This takes us directly into the sympotic context with which the Lydian harmonia is associated in the Republic. If the Lydians have contributed so much to the development of the Greek banquet ${ }^{77}$, it is more than plausible that what the Greeks knew as a 'Lydian aulos' was primarily associated with this aspect, just as its use by Pindar suggests. It contributed to the sense of elevated orientalising finesse

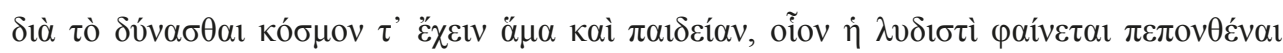
$\mu \alpha \dot{\lambda} \lambda \_\tau \alpha \tau \tilde{\omega} v \dot{\alpha} \rho \mu o v i \tilde{\omega} v$.

by its ability to combine elegance and culture, such as seems to be true for Lydian most of all harmoníai.

(Aristot., Pol. 1342b)

In this way, we arrive at a better explanation of our finds, while maintaining the idea that they would have been regarded as uniquely appropriate grave goods and therefore be more likely to appear in the archaeological record than other types ${ }^{78}$. Lydian auloi of their kind would not have mourned the deceased; instead, they accompanied them to the great banquet of afterlife, which we find so exceptionally depicted in the Tomb of the Diver.

\section{Bibliography}

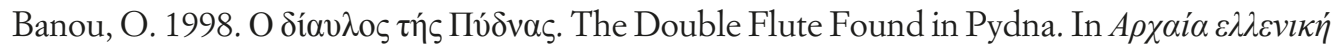

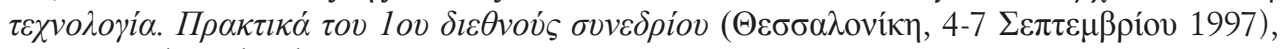
519-524. Thessaloniki.

Barker, A. 1989. Greek Musical Writings: Volume: II. Harmonic and Acoustic Theory. Cambridge: Cambridge University Press.

Barker, A. 1995. Heterophonia and Poikilia. Accompaniments to Greek Melody. In Gentili, B., Perusino, F. (eds.). Mousike. Metrica, ritmica e musica greca in memoria di Giovanni Comotti, 41-60. Pisa/Roma: Istituti Editoriali e Poligrafici Internazionali.

76 In terms of scalar logic, if 'Taut-Lydian' is taken to be the natural scale, 'Slack Lydian' would have to be notated with two flats. This place is later taken by the Hypophrygian key, whose modal antecedents would have been of altogether different shape.

77 Cfr. e.g. Franklin 2007; Węcowski 2014: 189-190.

78 The observed distribution of iconographical instrument lengths (cfr. n. 6 above) may similarly be explained by the prevalence of banqueting and merry-making contexts in vase paintings, while longer (Dorian?) pairs are found in more martial scenes. 
Barker, A. 2007. The Science of Harmonics in Classical Greece. Cambridge: Cambridge University Press.

Barker, A. 2016. Aristoxenus Harm. ii, 49.1-50.18 Da Rios: A Recantation. Greek and Roman Musical Studies 4: 90-102.

Becker, H. 1966. Zur Entwicklungsgeschichte der antiken und mittelalterlichen Robrblattinstrumente. Hamburg: Musikverlag H. Sikorski.

Bélis, A. 1984. Auloi grecs du Louvre. Bulletin de correspondance bellénique 108: 111-122.

Bodley, N.B. 1946. The Auloi of Meroë: A study of the Greek-Egyptian auloi found at Meroë, Egypt. American Journal of Archaeology 50: 217-240.

Brown, B. 2018. Descending Equi-Heptatonic Circuits. An Experimental Composition for Classical-Era Auloi with Diagrams and Commentary. Published online for the European Music Archaeology Project. [http://www.emaproject.eu/images/stories/pdf/euterpe/ Descending_Equi-heptatonic_Circuits_v1.pdf]

Byrne, M. 2000. Understanding the aulos. Studien zur Musikarchäologie (Orient-Archäologie) 2 (7): 279-285.

Closson, E. 1930. Une nouvelle série de hautbois égyptiens antiques. In Adler, G. (ed.). Studien zur Musikgeschichte. Festschrift für Guido Adler, 17-25. Wien: Universal-Edition.

Creese, D. 2010. The Monochord in Ancient Greek Harmonic Science. Cambridge: Cambridge University Press.

Curtis, J. 1914. The double flutes. The Journal of Hellenic Studies 34: 89-105.

Davidson, G.R. 1952. Corinth. Vol. XII: The Minor Objects; Results of Excavations Conducted by the American School of Classical Studies at Athens. Princeton (N.J.): American School of Classical Studies at Athens.

Franklin, J.C. 2007. 'A Feast of Music': The Greco-Lydian Musical Movement on the Assyrian Periphery. In Collins, B.J., Bachvarova, M., Rutherford, I. (eds.). Anatolian Interfaces: Hittites, Greeks and Their Neighbors, 193-203. Oxford: Oxbow Books.

Hagel, S. 2000. Modulation in altgriechischer Musik: Antike Melodien im Licht antiker Musiktheorie. Frankfurt: Peter Lang.

Hagel, S. 2004. Calculating Auloi - the Louvre Aulos Scale. Studien zur Musikarchäologie (Orient-Archäologie) 4 (15): 373-390.

Hagel, S. 2005. Twenty-four in Auloi. Aristotle, Met. 1093b, the Harmony of the Spheres, and the Formation of the Perfect System. In Hagel, S., Harrauer, C. (eds.). Ancient Greek Music in Performance, 51-91. Vienna: Verlag der Österreichische Akademie der Wissenschaften.

Hagel, S. 2008. Re-evaluating the Pompeii Auloi. The Journal of Hellenic Studies 128: 52-71.

Hagel, S. 2009. Ancient Greek. Music: A New Technical History. Cambridge: Cambridge University Press.

Hagel, S. 2010. Understanding the Aulos Berlin Egyptian Museum 12461/12462. Studien zur Musikarchäologie (Orient-Archäologie) 7/25: 67-87.

Hagel, S. 2012a. The Pompeii Auloi: Improved Data and a Hitherto Unknown Mechanism. Studien zur Musikarchäologie (Orient-Archäologie) 8 (27): 103-114.

Hagel, S. 2012b. Review of D. Creese, The Monochord in Ancient Greek Harmonic Science. Aestimatio 9: 337-351. 
Hagel, S. 2013. Aulos and Harp: Questions of Pitch and Tonality. Greek and Roman Musical Studies 1: 151-171.

Hagel, S. 2014. Better Understanding the Louvre Aulos. Studien zur Musikarchäologie (OrientArchäologie) 9 (33): 131-142.

Hagel, S. 2019a. Reconstructing the Auloi from Queen Amanishakheto's Pyramid. Studien zur Musikarchäologie (Orient-Archäologie) 11 (40): 177-197.

Hagel, S. 2019b. Shaping Characters: An Ancient Science of Musical Ethos? In Lawson, G., Eichmann, R., Howell, M. (eds.). Music and Politics in the Ancient World: Exploring Identity, Agency, Stability and Change through the Records of Music Archaeology (Berlin Studies of the Ancient World 65), 87-103. Berlin: Pro Business.

Hogarth, D.G. 1908. Excavations at Ephesus: The Archaic Artemisia. London: British Museum.

Howard, A.A. 1893. The Aủiós or Tibia. Harvard Studies in Classical Philology 4: 1-60.

Landels, J.G. 1963. The Brauron Aulos. Annual of the British School at Athens 58: 116-119.

Lawergren, B. 1993. Lyres in the West (Italy, Greece) and East (Egypt, the Near East) ca. 2000 to 400 B.C. Opuscula Romana 19: 55-76.

Letters, R.J. 1969. The Scales of some Surviving Auloi. The Classical Quarterly 19: 266-268.

Loret, V. 1893. Sur une ancienne flute égyptienne découverte dans les ruines de Panopolis. Publications de la Société Linnéenne de Lyon 12: 91-101.

Lynch, T. 2017. The Symphony of Temperance in Republic 4. Greek and Roman Musical Studies 5: 18-34.

Najock, D. 1996. Aristoxenos und die Auloi. In Faber, R., Seidensticker, B. (eds.). Worte. Bilder. Töne. Studien zur Antike und Antikerezeption, 59-76. Würzburg: Königshausen \& Neumann.

Olsen, P.R. 1968. An Aulos in the Danish National Museum. Dansk Arbog for Musikforskning 1966-7: 1-9.

Orsi, P. 1917. Locri Epizefiri. Campagne di scavo nella necropoli Lucifero negli anni 1914 e 1915. Notizie degli Scavi 1917: 101-167.

Paquette, D. 1984. L'Instrument de Musique dans la Céramique de la Grèce antique. Études d'Organologie. Paris: De Boccard.

Pöhlmann, E., West, M.L. 2001. Documents of Ancient Greek Music: The extant melodies and fragments. Oxford: Oxford University Press.

Psaroudakes, S. 2002. The Aulos of Argithea. Studien zur Musikarchäologie (OrientArchäologie) 3 (10): 335-366.

Psaroudakes, S. 2008. The Auloi of Pydna. Studien zur Musik-Archäologie (Orient-Archäologie) 6 (22): 197-216.

Psaroudakēs, S. 2014. The Aulos of Poseidonia. In Bellia, A. (ed.). Musica, culti e riti nell'Occidente greco (Telestes. Studi e ricerche di archeologia musicale nel Mediterraneo 1), 117 129. Pisa/Roma: Istituti Editoriali e Poligrafici Internazionali.

Reichlin, P.J., Reichlin-Moser, B. 2015. Der Paestum Aulos aus der Tomba del Prete. Samstagern: Atelier für Geigenbau. 
Schlesinger, K. 1939. The Greek Aulos: A Study of its Mechanism and of its Relation to the Modal System of Ancient Greek Music, followed by a Survey of the Greek. Harmoniai in Survival or Rebirth in Folk-Music. London: Methuen \& Co.

Southgate, T.L. 1915. Ancient Flutes from Egypt. The Journal of Hellenic Studies 35: 12-21.

Steinmann, C., Reichlin, P.J. 2006. Instruments and their Music from the 5th Century BC in Classical Greece. Studien zur Musikarchäologie (Orient-Archäologie) 5 (20): 237-254.

Tsuge, G. 2013. Musical Instruments Described in a Fourteenth-Century Persian Treatise 'Kanz al-tuhaf'. The Galpin Society Journal 66: 165-259.

Węcowski, M. 2014. The Rise of the Greek Aristocratic Banquet. Oxford: Oxford University Press.

Wegner, M. 1949. Das Musikleben der Griechen. Berlin: De Gruyter.

West, M.L. 1981. The Singing of Homer and the Modes of Early Greek Music. The Journal of Hellenic Studies 101: 113-129.

West, M.L. 1992. Ancient Greek Music. Oxford: Oxford University Press.

Winnington-Ingram, R.P. 1932. Aristoxenus and the Intervals of Greek Music. The Classical Quarterly 26: 195-208.

Winnington-Ingram, R.P. 1936. Mode in Ancient Greek. Music. Cambridge: Cambridge University Press.

Winnington-Ingram, R.P. 1939. The Greek Aulos. Journal of Hellenic Studies 59: 305-307. 
